\title{
International Journal of Primatology \\ An enigmatic hypoplastic defect of the maxillary lateral incisor in recent and fossil orangutans from Sumatra (Pongo abelii) and Borneo (Pongo pygmaeus). \\ --Manuscript Draft--
}

\begin{tabular}{|c|c|}
\hline Manuscript Number: & IJOP-D-16-00106R3 \\
\hline Full Title: & $\begin{array}{l}\text { An enigmatic hypoplastic defect of the maxillary lateral incisor in recent and fossil } \\
\text { orangutans from Sumatra (Pongo abelii) and Borneo (Pongo pygmaeus). }\end{array}$ \\
\hline Article Type: & Original Article \\
\hline Keywords: & infancy; dentition; growth; paleohealth; Lufengpithecus; Anapithecus \\
\hline Corresponding Author: & $\begin{array}{l}\text { Mark Fretson Skinner, Ph.D. } \\
\text { University of York } \\
\text { York, North Yorkshire UNITED KINGDOM }\end{array}$ \\
\hline \multicolumn{2}{|l|}{$\begin{array}{l}\text { Corresponding Author Secondary } \\
\text { Information: }\end{array}$} \\
\hline Corresponding Author's Institution: & University of York \\
\hline \multicolumn{2}{|l|}{$\begin{array}{l}\text { Corresponding Author's Secondary } \\
\text { Institution: }\end{array}$} \\
\hline First Author: & Mark Fretson Skinner, Ph.D. \\
\hline \multicolumn{2}{|l|}{ First Author Secondary Information: } \\
\hline \multirow[t]{4}{*}{ Order of Authors: } & Mark Fretson Skinner, Ph.D. \\
\hline & Matthew M. Skinner, Ph.D. \\
\hline & Varsha C. Pilbrow, Ph.D. \\
\hline & Darcy L. Hannibal, Ph.D. \\
\hline \multicolumn{2}{|c|}{ Order of Authors Secondary Information: } \\
\hline Manuscript Region of Origin: & UNITED KINGDOM \\
\hline \multicolumn{2}{|l|}{ Funding Information: } \\
\hline Abstract: & $\begin{array}{l}\text { Developmental dental pathologies provide insight into health of primates during } \\
\text { ontogeny, and are particularly useful for elucidating the environment in which extant } \\
\text { and extinct primates matured. Our aim is to evaluate whether prevalence of an unusual } \\
\text { dental defect on the mesio-labial enamel of the upper lateral incisor, thought to reflect } \\
\text { dental crowding during maturation, is lesser in female orangutans, with their smaller } \\
\text { teeth, than males, and Sumatran orangutans, from more optimal developmental } \\
\text { habitats, than those from Borneo. Our sample includes } 49 \text { Pongo pygmaeus ( } 87 \\
\text { teeth), } 21 \text { P. abelii ( } 38 \text { teeth), Late Pleistocene paleo-orangutans from Sumatra and } \\
\text { Vietnam ( } 67 \text { teeth), Late Miocene catarrhines Lufengpithecus lufengensis ( } 2 \text { teeth) and } \\
\text { Anapithecus hernyaki ( } 7 \text { teeth). Methods include micro-CT scans, radiography and } \\
\text { dental metrics of anterior teeth. We observed fenestration between incisor crypts and } \\
\text { marked crowding of unerupted crowns, which could allow tooth-to-tooth contact. Tooth } \\
\text { size does not differ significantly in animals with or without the defect, implicating } \\
\text { undergrowth of the jaw as the proximate cause of dental crowding and defect } \\
\text { presence. Male orangutans from both islands show more defects than females. The } \\
\text { defect is significantly more common in Bornean orangutans (71\%) compared to } \\
\text { Sumatran ( } 29 \% \text { ). Prevalence among fossil forms falls between these extremes, except } \\
\text { that all five individual Anapithecus show one or both incisors with the defect. We } \\
\text { conclude that maxillary lateral incisor defect is a common developmental pathology of } \\
\text { apes that is minimized in optimal habitats and that such evidence can be used to infer } \\
\text { habitat quality in extant and fossil apes. }\end{array}$ \\
\hline
\end{tabular}


Dear Dr. Setchell:

Re: MS IJOP-D-16-00106

Thank you for your final suggested edits which I have made. I confirmed the author's name is Powe.

I will now proceed to final submission.

Regards

Mark 


\section{Response to Reviewer:}

Firstly, I have made the changes requested by the Editor (just to be clear, no chimpanzees were examined for MLID in this study, only radiographed to get an idea of incisor crown formation in apes).

Secondly, I have simplified and enlarged Figure 3 (which relates to the topic just mentioned) and which the reviewer found difficult to read (as are all radiographs which are being replaced instrumentally by CT scans (our Figure 4)).

As recommended I have added into the Results section a small component to the micro-morphological observations; viz., The purpose of Figure 6 is to show close-up morphological details of the outer enamel surface in: normal enamel; an area affected by MLID; as well as linear enamel hypoplasia. MLIDs show exposed Tomes' process pits in the floor of a plane form defect. In addition, I have added, as recommended symbols to Figure 6 to try to make the observations in the dense prose from the Figure caption a bit more understandable.

Then, as recommended, I have added a larger section to the Discussion as follows:

Our micro-morphological analysis, which is limited to only the outer enamel surface of a cast (Fig. 6), found exposed Tomes' process pits in the floor of the defect. It can be concluded that there occurred an abrupt cessation of matrix secretion without recovery of function, at least centrally within the defect. At the time, the affected ameloblasts still possessed the distal portion of their Tomes' processes (Witzel, Kierdorf, Schulz, \& Kierdorf, 2008). It can be inferred that, in terms of etiology, the proximate causative agent was a short-term event affecting a localized group of cells. This scenario is compatible with a sudden breaching of the inter-crypt septum creating a fenestration. Rather than invoking a gradual compression of a tooth crown within an unyielding crypt-a physical process that would have been detectable as a graduated secretory response from the ameloblast-it seems more likely, given the ledge-like appearance of many of the MLIDs (Fig. 5), that there was relatively abrupt abnormal contact of the developing crown with the sharp edge of a crypt fenestration. Histological thin sections of original teeth with MLID will be required to resolve these speculations.

Lastly, regarding Island differences and the reviewers concern about over-stressing habitat quality as an explanation, I have added the following caveat:

Rather than arguing for differences in habitat quality, it may be germane that lactation, which presumably provides a reasonably assured component of the infant's food requirements, is prolonged significantly longer in Sumatran than Bornean orangutans (van Noordwijk et al., 2013). 
Title: An enigmatic hypoplastic defect of the maxillary lateral incisor in recent and fossil orangutans from Sumatra (Pongo abelii) and Borneo (Pongo pygmaeus).

Authors: Mark F. Skinner ${ }^{1}$

Matthew M. Skinner ${ }^{2,3}$

Varsha C. Pilbrow ${ }^{4}$

Darcy L. Hannibal ${ }^{5,6}$

1. Correspondence should be addressed to: mskinner@sfu.ca, +4407583 412295, Department of Archaeology, King's Manor, University of York, York, YO1 7EP, United Kingdom

2. School of Anthropology and Conservation

University of Kent

Marlowe Building

Canterbury, UK, CT2 7NR

3. Department of Human Evolution

Max Planck Institute for Evolutionary Anthropology

Leipzig, Germany, 04103

4. Department of Anatomy and Neuroscience

University of Melbourne

Parkville, VIC, 3010, Australia

5. Department of Population Health and Reproduction

University of California, Davis

One Shields Ave

Davis, CA 95616

6. Brain, Mind and Behavior Unit

California National Primate Research Center

University of California, Davis

One Shields Ave

Davis, CA 95616 


\section{Acknowledgments}

MFS acknowledges helpful discussions or assistance from Heather Edgar, David

Hopwood, Paul Klassen, Laszlo Kordos, Meg Stark, Vu The Long, and Ji Xueping. DLH would like to thank Linda Gordon and Richard Thorington, Department of Mammals, Smithsonian National Museum and Natural History for access to specimens, catalog records, field notes, and facilities and the University of Oregon Graduate Student Research Award program for financial support. For access to specimens for CT scanning we thank Thomas Koppe and the Greifswald Anatomy Museum, Germany. This research was supported by the Max Planck Society, National Science Foundation (SBR-9815546), the Wenner-Gren Foundation, and the Leakey Foundation. Lastly, we are grateful to the editor and two anonymous reviewers for their patience and excellent advice. 
Title: An enigmatic hypoplastic defect of the maxillary lateral incisor in recent and fossil orangutans from Sumatra (Pongo abelii) and Borneo (Pongo pygmaeus).

Authors: Mark F. Skinner ${ }^{1}$

Matthew M. Skinner ${ }^{2,3}$

Varsha C. Pilbrow ${ }^{4}$

Darcy L. Hannibal ${ }^{5,6}$

1. Correspondence should be addressed to: mskinner@sfu.ca, +44 07583 412295, Department of Archaeology, King's Manor, University of York, York, YO1 7EP, United Kingdom

2. School of Anthropology and Conservation University of Kent

Marlowe Building

Canterbury, UK, CT2 7NR

3. Department of Human Evolution

Max Planck Institute for Evolutionary Anthropology

Leipzig, Germany, 04103

4. Department of Anatomy and Neuroscience

University of Melbourne

Parkville, VIC, 3010, Australia

5. Department of Population Health and Reproduction

University of California, Davis

One Shields Ave

Davis, CA 95616

6. Brain, Mind and Behavior Unit

California National Primate Research Center

University of California, Davis

One Shields Ave

Davis, CA 95616 


\section{Abstract}

39 Developmental dental pathologies provide insight into health of primates during ontogeny,

40 and are particularly useful for elucidating the environment in which extant and extinct

41 primates matured. Our aim is to evaluate whether prevalence of an unusual dental defect

42 on the mesio-labial enamel of the upper lateral incisor, thought to reflect dental crowding

43 during maturation, is lesser in female orangutans, with their smaller teeth, than males; and

44 Sumatran orangutans, from more optimal developmental habitats, than those from Borneo.

45 Our sample includes 49 Pongo pygmaeus (87 teeth), 21 P. abelii (38 teeth), Late Pleistocene

46 paleo-orangutans from Sumatra and Vietnam (67 teeth), Late Miocene catarrhines

$47 \quad$ Lufengpithecus lufengensis (2 teeth) and Anapithecus hernyaki (7 teeth). Methods include

48 micro-CT scans, radiography and dental metrics of anterior teeth. We observed

49 fenestration between incisor crypts and marked crowding of unerupted crowns, which

50 could allow tooth-to-tooth contact. Tooth size does not differ significantly in animals with

51 or without the defect, implicating undergrowth of the jaw as the proximate cause of dental

52 crowding and defect presence. Male orangutans from both islands show more defects than

53 females. The defect is significantly more common in Bornean orangutans (71\%) compared

54 to Sumatran (29\%). Prevalence among fossil forms falls between these extremes, except

55 that all five individual Anapithecus show one or both incisors with the defect. We conclude

56 that maxillary lateral incisor defect is a common developmental pathology of apes that is

57 minimized in optimal habitats and that such evidence can be used to infer habitat quality in

58 extant and fossil apes.

59

60 Key words: infancy; dentition; growth; paleohealth; Lufengpithecus; Anapithecus 


\section{Introduction}

62 Primate growth is a reflection of metabolic function as influenced by nutritional and

63 disease factors within particular habitats (Altmann 1998). As large, slow-growing

64 mammals, whose tooth formation may span several years of nutritional and disease

65 seasonal cycles, the dental maturation of apes in the wild is sensitive to developmental

66 conditions (Zihlman et al. 2007). Teeth form within bone. Where cranio-facial bone growth

67 has been insufficient, erupted teeth in the adult mammal may be crowded and mal-

68 occluded (DiOrio et al. 1973; Luke et al. 1979; Thomaz et al. 2010; Tonge and McCance

69 1973). A mild relationship in humans was found between growth deficit (height for age)

70 and malnutrition and crowding of permanent teeth (2010). Severely undernourished pigs

71 show third molar impaction due to undergrowth of jaws in length (McCance and Ford

72 1961) and severe dental crowding with direct contact between adjacent teeth (Tonge and

73 McCance 1973). Calorie deficiency has a greater negative impact on jaw growth than does

74 protein deficiency (Luke et al. 1979). Experimental protein under-nutrition in rats induces

75 catabolism of muscle (including chewing muscles), reduced jaw size and dental crowding

76 (Garat et al. 2007). Non-human primates are no exception. A low protein diet in squirrel

77 monkeys delayed growth and shape changes, particularly in the masticatory region

78 (Dressino and Pucciarelli 1997).

79

80 Prior to eruption, dental crowns are normally sequestered in their own crypts during

81 formation; consequently there is almost no consideration of pre-eruptive dental crowding.

82 Indeed it has been remarked that "future studies of primate tooth development should

83 include data on times of crypt initiation and rates of crypt enlargement, without which 
84 analyses of dental development are incomplete" (Boughner and Dean 2004) (P. 274).

85 Although these authors emphasize genetic control of taxonomic variation in normal

86 available space for successive crown mineralization, they also note that physiological or

87 physicochemical factors may establish baseline minimum distance maintained between

88 teeth from their inception. On occasion, alveolar bone (the inter-dental septum) that

89 normally separates crypts, may not be maintained, such that inter-crypt fenestration

90 occurs. Good evidence for crypt fenestration, labially or buccally, has been shown in the

91 case of localized hypoplasia of the primary canine (LHPC) in humans and apes (Skinner

92 1986, 2000; Skinner and Hung 1989; Skinner and Newell 2003) and a comparable defect of

93 the maxillary molars of pigs (Skinner et al. 2014). In terms of ultimate causation of crypt

94 fenestration defects, evidence suggests that vitamin A deficiency or reduced bioavailability

95 explains instances of LHPC in humans and other apes (Skinner et al. 1994; Skinner and

96 Newell 2003); and the combined effects of sickness and malnutrition in pigs (Skinner et al.

97 2014).

98

99 Ephemeral fenestration between adjacent crypts can allow contact in primary human teeth

100 (Lukacs 1999). For example, Lukacs describes areas of missing enamel on mesial and distal

101 surfaces of primary canines and on the mesial surface of molar teeth in archaeological

102 samples, terming these interproximal contact hypoplasias (IPCH). He suggests that in such

103 cases (about 15\%) there was abnormally slow longitudinal growth of the jaws in infancy.

104 Enamel defects in IPCH range from single or confluent circular pits (ca. $0.5 \mathrm{~mm}$ in diameter)

105 to "basins" several mm in length and breadth. Usually they are plane-form defects 
106 "characterized by a broad area of deficient enamel...near the area of maximal mesial or

107 distal curvature of the crown" (Lukacs 1999) (P. 723). He writes:

108 The proximate etiology of IPCH is tooth-tooth contact through fenestrae in the inter109 dental septum due to anterior/posterior compaction of the developing dentition. Developmental disruptions in bone growth due to nutritional or pathological insult, combined with underuse and consequent reduction of the jaws, are possible factors involved in the etiology of IPCH (ibid, p. 732).

114 Thus, it is reasonable to expect that compromised nutrition in infant apes will affect jaw

115 growth and possibly produce dental crowding, crypt fenestration, and contact hypoplasias.

117 Orangutans (Pongo species) were at one time broadly distributed from Southern China to

118 Java. Despite their clear success throughout a huge latitudinal range, orangutans are

119 described as having strict habitat requirements (i.e., evergreen wet forest) (Nater et al.

120 2011). During glacial periods of the Pleistocene, the climate in Sumatra was cooler, drier

121 and more seasonal (Harrison et al. 2006; Meijaard 2003). A review of the ecological

122 correlates of fossil orangutan find spots indicates that orangutans likely retreated to forest

123 refugia during the Pleistocene dessication which affected parts of the Sundaic region

124 (Ibrahim et al. 2013). Late Pleistocene environments of Sumatra are reconstructed on

125 ecological grounds to have been warm and wet, similar to today (Louys and Meijaard

126 2010). West Sumatra remained forested (Meijaard 2003). Nevertheless, land temperatures

127 during cold phases of the Pleistocene may have decreased by as much as $3-5^{\circ} \mathrm{C}$ (Harrison et 128 al. 2006).

130 At the end of the last ice age, a rapid rise in sea level isolated orangutans on the islands of 131 Borneo and Sumatra (Harrison et al. 2006), creating contrasting habitats to which they 
132 have been adapting for some 14,000 years (Hanebuth et al. 2000). Bornean mammals, in

133 general, tend to be smaller than conspecifics in other locations, attributable to lower

134 primary productivity on relatively less fertile soils on Borneo (Meiri et al. 2008; Wich et al.

135 2011). There are several lines of evidence which suggest that Sumatra may currently

136 provide a superior habitat for orangutans due, fundamentally, to volcanically-derived soils

137 (Wich et al. 2011). Sumatran forests show higher soft-pulp fruit production, generally, and

138 throughout the seasons (Delgado and van Schaik 2000). Unlike Bornean orangutans (Pongo

139 pygmaeus), Sumatran orangutans (Pongo abelii) spend more time eating high-quality foods

140 such as fruit and insects and less time eating bark and vegetation (Russon et al. 2009).

141 Moreover, Sumatran orangutans seem less reliant on fallback foods than are Bornean

142 orangutans, being able to find figs and fruit year round (Russon et al. 2009). In Borneo,

143 there are months when fruit is a minor part of the diet whereas, in Sumatra, fruit is always

144 a major part of the diet (Morrogh-Bernard et al. 2009). Not surprisingly, orangutan

145 population density is higher in Sumatra than in Borneo (van Schaik et al. 2009). However,

146 our assessment of the Sumatran habitat for orangutans may be skewed by the high

147 densities of animals inhabiting the Kluet, Singkil and Tripa swamps in the northern corner

148 of the island whose peat soils are regularly inundated by rivers and run-off from adjacent

149 hills that bring minerals from the Leuser mountains, creating an optimum habitat for

150 growth and development that is judged to be exceedingly rare in Borneo (Husson et al.

151 2009).

152

153 In this study, we investigate an unusual dental defect that may be a marker of under-

154 developed cranio-facial growth in great apes. Maxillary lateral incisor defects (MLIDs) are 
155 abnormalities of the mesio-labial enamel contour on the upper lateral incisor (Hannibal 156 2003) visible as pit, plane-form and/or notch defects, varying from a tiny dimple to a major

157 cleft occasionally affecting crown/root orientation (Fig. 1). MLIDs have been tentatively

158 attributed to a combination of systemic stress and local anatomical factors leading to pre-

159 eruptive, developmental crowding; to date, their presence is restricted to apes, especially

160 orangutans among whom they were reported to occur in about one-third of animals

161 (Hannibal 2003). Intriguingly, there are no human examples of MLID, although the more

162 severe examples of the defect reported below may have a parallel in the so-called J-shaped,

163 Etruscan Upper Lateral Incisor; however, the latter condition is located more mesio-

164 lingually (Pinto-Cisternas et al. 1995).

165

166

167 Our aims are to: 1) elucidate the proximate cause of MLID; and 2) determine whether

168 orangutan samples from different spatio-temporal contexts exhibit different frequencies of

169 MLIDs. To accomplish the first aim we examine radiographic and microtomographic scans

170 of developing dentitions of chimpanzees (Pan troglodytes troglodytes) and orangutans,

171 respectively. We then characterize variation in anatomical location and type of defect in a

172 range of catarrhine primates and test for correlations between MLID frequency and

173 anterior tooth size and sex since mild to marked sex differences in anterior tooth size,

174 especially for the canine, could potentially affect the degree of anterior tooth crowding and

175 the likelihood of MLID occurring. To accomplish the second aim we compare MLID

176 frequency between extant orangutans from Borneo and Sumatra and between each extant

177 sample and samples of Vietnamese and Sumatran paleo-orangutans. We predict that, were 
178 the growth of an infant ape to falter, the physical relationships of the upper anterior teeth

179 will predispose them to MLID; specifically that the formation of the crown of the upper

180 lateral incisor should overlap that of the forming upper central crown, but will be later in

181 time and physically behind it; and that inter-crypt fenestration can occur. Moreover, MLID

182 should take the form of pits and plane-form depressions in the outer enamel surface and

183 resemble those described for inter-proximal contact hypoplasias in primary teeth (Lukacs

184 1999).

185

186 Fossil assemblages are likely to be composed of those individuals who died before their

187 time; i.e., they form a biased subset selected out of the living assemblage-a mortality cohort

188 (Wood et al. 1992). We predict that MLID will be more common in mortality cohorts

189 reflective of attritional deaths (most fossil assemblages) rather than catastrophic mortality

190 (hunted assemblages) (DeWitte and Stojanowski 2015; Wood et al. 1992). Additionally, we

191 predict that MLID will be more frequent among Bornean orangutans with relatively

192 impoverished soils (Meiri et al. 2008) than among Sumatran orangutans from more

193 optimal habitats (Husson et al. 2009). Furthermore, MLID will be more common in

194 Sumatran paleo-orangutans than extant orangutans, due to amelioration of habitats in the

195 Holocene (Meijaard 2003).

198 Methods

199 Given the comparative and epidemiological nature of this study including, potentially,

200 innate, ontogenetic and nutritional factors, we cannot determine the etiology of MLID with 
201 certainty. This would require a specimen with demonstrably compromised development in 202 which an unerupted central incisor is creating a divot in a lateral incisor. To evaluate the 203 inference that a defect of formation on the mesio-labial surface of the permanent upper 204 lateral incisor (MLID) may be attributable to physical contact between forming incisor 205 crowns while still in their crypts, we compared radiographs of two immature chimpanzees, 206 from the region between Batouri and Lomie, Cameroon whose crania are curated in the 207 Powell-Cotton Museum, Quex Park, U.K.. We also imaged an immature recent orangutan 208 maxilla, probably Sumatran in origin (Thomas Koppe pers. comm.), borrowed from the 209 Institut für Anatomie und Zellbiologie Universitätsmedizin Greifswald, using a BIR ACTIS $210225 / 300$ high-resolution micro-CT scanner $(130 \mathrm{kV}, 100 \mu \mathrm{A}, 0.25$ brass filter, 1250

211 projections, 2 frame averaging, resultant isometric voxel size was $30 \mu \mathrm{m}$ ) housed at the 212 Department of Human Evolution, Max Planck Institute for Evolutionary Anthropology 213 (Leipzig, Germany). We segmented the tooth crypts and associated alveolar bone manually 214 in Avizo 6.3® (Visualization Sciences Group, SAS) and created surface models of tissues 215 using the surface generation module.

\section{Study sample}

218 Our sample included 70 recent orangutans (Table 1). Most of these were taken from the 219 wild in the early 1900s with locations documented by collectors (Table 1). All recent

220 Sumatran animals in this study derive from the northern province of Aceh (especially the 221 Medan area (Drawhorn 1994)) while the Bornean animals sample all three subspecies of $P$. 222 pygmaeus (Wich et al. 2008) (Fig. 2). 
225 We examined 76 fossil hominoid incisors for MLID (Table 2). We selected fossils either

226 because they are thought to be related to modern orangutans, or because the collection

227 contains a comparatively large number of upper lateral incisors. Our sample includes five

228 individual Anapithecus hernyaki represented by seven upper lateral incisors (Kordos and

229 Begun 2001; Nargolwalla et al. 2005) from the site of Rudabanya, Hungary, which is Late

230 Miocene (MN 9, 11.2 - 9.7 Ma) in age (Andrews and Cameron 2010; Begun et al. 2006).

231 Anapithecus is considered to be a small-bodied catarrhine, probably a pliopithecoid

232 (Kordos and Begun 2002). The site is located in a valley on what was once a peninsula, 1-2

233 km wide, projecting into the Central Paratethys sea (Kordos and Begun 2002). The

234 relatively large number of individuals and their immaturity suggest that the locality may

235 have provided an optimum habitat for the primate close to the core area of the home range

236 where most juveniles would be concentrated (Andrews and Cameron 2010).

238 We included two Lufengpithecus, which is thought to be a close relative of orangutans

239 (Harrison 2010). These fossils are from the site of Shi-Hui-Ba in Yunnan Province, China,

240 which consists of lignite deposits, judged to be Late Miocene (6.9-5.8 Ma) in age (Qi et al.

241 2006; Zhao et al. 2008), formed in beaver ponds into which the arboreal ape

242 Lufengpithecus fell (Badgley et al. 1988).

244 Fossil orangutans from Mainland Asia and Sumatra have larger teeth (ca. 15-20\%) than

245 recent orangutans (Smith et al. 2011) which may predispose them to MLID. The paleo-

246 Sumatran orangutans in our sample are from several poorly dated cave sites in the Padang 
247 Highlands, all of which can be considered Late Pleistocene (Table II, but see Harrison et al.

248 (2006)). The sample is made up, overwhelmingly, of teeth thought to derive from

249 porcupine nests which census a mortality cohort rather than a catastrophic-type

250 assemblage (Drawhorn 1994). There are 56 teeth from a minimum of 38 individuals. There

251 are currently no orangutans in southern Sumatra from where the fossil orangutans used in

252 this study are drawn. The Padang Highlands are south of the putative ecological Mt. Toba

253 volcano barrier (Wilting et al. 2012), suggesting that the paleo-Sumatran orangutans may

254 be genetically closer to extant Bornean than to north Sumatran orangutans.

255

256 The fossil orangutans from Vietnam in our study come from five cave sites ranging in age

257 from Late Middle to Late Pleistocene (Table II). The paleo-environment of the Late

258 Pleistocene orangutan sites of Hang Hum in Vietnam may have been more open/mixed

259 than observed at lower latitudes (Louys and Meijaard 2010). There are 11 teeth from a

260 minimum of 10 individuals.

261

262

\section{Imaging and measurement}

264 We made observations on original teeth for simple presence/absence of a defect in the

265 labial enamel contour (we ignored evidence of linear enamel hypoplasia) and then made

266 casts of more salient examples in araldite for examination at higher magnifications and for

267 illustrative purposes. Acknowledging that customary dental metrics on fully-formed

268 anterior tooth crowns may not have much relevance for transitory size during ontogeny of

269 tightly packed, differentially-formed, incomplete crowns prior to eruption, we,

270 nevertheless, collected traditional measures of incisor crowns (Hillson 1996) with Moore- 
271 Wright electronic calipers $(+/-0.01 \mathrm{~mm})$ on European collections, and on teeth from

272 American museums using sliding calipers, calibrated to the nearest $0.01 \mathrm{~mm}$. We measured

273 mesio-distal length at the incisal edge, labio-lingual breadth at midpoint of the cervical-

274 incisal axis, and labial height from incisal edge to cervical margin on the labial aspect

275 (Pilbrow 2006). Our observations of MLID were incidental to other studies. Consequently,

276 we did not collect metrics on affected and unaffected teeth, except for those taken on paleo-

277 orangutans. Nevertheless, we could combine separate studies that fortuitously include the

278 same specimens.

279

280 We conducted macro-photography with a Keyence digital microscope VHX-100 and used a

281 Fisher Portable $200 \mathrm{x}$-ray machine (preset at 65 peak kilovoltage) to radiograph the

282 immature chimpanzee maxillae. We measured depth of defects on casts with a $\mu$ surf mobile

283 scanner, manufactured by NanoFocus AG, Oberhausen. We took measurements from a

284 single profile which traversed the deepest point of the defect parallel to the longitudinal

285 axis of the crown (so-called N-S axis), even though some defects are angled (Fig. 1, 5). We

286 took scanning electron micrographs of a cast with MLID in the imaging facility at the

287 University of York with a JEOL JSM-6490LV instrument.

\section{Statistical analysis}

290 In that observation of a defect was often not purposive, but incidental to other studies, the

291 prevalence statistics reported below are probably conservative. Because fossil assemblages

292 are typically comprised of isolated teeth that cannot be reliably assigned to individual

293 animals, it is rarely possible to match right and left teeth from an individual or to identify 
294 sex. Hence, statistical analysis is performed in terms of only lefts, and only rights, compared 295 to the same in recent orangutans. We used Chi Square and Fisher's Exact Test (when any

296 cell frequency is $<6$ ) to examine differences in prevalence of the defect between islands and 297 sexes; and Student's ' $t$ ' test for the effect of tooth size, performed with SPSS 22 (IBM 2013).

298 We set alpha at 0.05 .

299

300 Results

301 Aim 1: the proximate cause of MLID

302 Radiographs of the upper jaw of infant chimpanzees (Fig. 3) show that central incisor

303 crown mineralization is advanced slightly over the lateral incisor but that the crypt for the

304 lateral incisor is situated further occlusally in some specimens (e.g., M475). Micro-CT scans

305 of an orangutan infant upper jaw show that, prior to eruption, the lateral incisor is located

306 behind the central and that fenestration can occur between incisor crypts (Fig. 4). 307

309 These variable anatomic relationships show that the precise points of contact between

310 incisor crowns vary. Defect locations, shape and size are also variable (Fig. 5). Most are

311 found on the mesio-labial contour of the lateral incisor crown in the cervical half and

312 occasionally encroaching onto the root. Size varies from a small dimple on the cingulum,

313 through a 1 to $2 \mathrm{~mm}$ length notch angling mesio-incisally, to a large wedge-shaped defect

314 with distorted alignment of crown and root. The full range of defect severity goes beyond

315 enamel hypoplasia to include effects on dentin formation. They resemble the pits and

316 plane-form depressions described for inter-proximal contact hypoplasias in human 
317 primary teeth (Lukacs 1999) (Fig $5 \mathrm{~A}$ and E) but also include the very distinctive diagonal

318 ledges first noted by Hannibal (2003) (Fig 5 B and C); as well as gross distortion of crown

319 and root alignment (Fig 5 D).

320

321

322 Scanning electron microscopy of a large defect (Fig. 6) shows close-up morphological

323 details of three varieties of outer enamel surface: normal enamel (Fig 6H), an area affected

324 by MLID (Fig 6D), and linear enamel hypoplasia (Fig 6A).

325

326

327 Effects of sex and tooth size

328 MLID is significantly more common in males than females for Borneo, but not for Sumatra,

329 at both the tooth and the individual level (Table III).

330

331

332 We found no significant size differences between teeth from individuals with or without

333 MLID (Table IV). However, in 11 out of 13 comparisons, individuals with MLID had, on

334 average, bigger teeth (higher z-scores) than those without.

335

336

337

338 We found no significant differences between teeth with or without MLID in any dental measure for both the paleo-Sumatran and Bornean orangutan samples (Table V). 
342 Overall, MLID in recent animals occurs in 57\% of upper lateral incisors and 59\% of

343 individuals taken from the wild. Bilateral symmetry of the presence of MLID is the norm

344 (91\%). There are no side differences in the occurrence of MLID in the combined orangutan

345 sample (Chi Square $=0.111, \mathrm{df}=1, \mathrm{P}=0.740$ ), nor in Bornean or Sumatran orangutans

346 considered separately (Chi Square $=0.843, \mathrm{df}=1, \mathrm{P}=0.358$; Chi Square $=0.038, \mathrm{df}=1, \mathrm{P}=0.846$,

347 respectively) (Table VI).

348

349 Aim 2: Do orangutan samples from different spatio-temporal contexts exhibit

350 different frequencies of MLIDs?

351

352 Cohort source

353 The prevalence of MLID is significantly higher in the paleo-Sumatran orangutans than in

354 recent Sumatran orangutans (Table VI, Left side - Pearson Chi Square=6.222, P=0.013;

355 Fisher's Exact Test $\mathrm{P}=0.028$; Right side - Pearson Chi Square=8.125, $\mathrm{P}=0.004$; Fisher's Exact

356 Test $\mathrm{P}=0.009$ ), but does not differ significantly from recent Bornean orangutans (Left side -

357 Pearson Chi Square $=0.004, \mathrm{P}=0.952$; Fisher's Exact Test $\mathrm{P}=1.000$; Right side - Pearson Chi

358 Square $=0.756, \mathrm{P}=0.384$; Fisher's Exact Test $\mathrm{P}=0.440$ ).

359

360 Sample sizes for other fossil forms are too small for statistical analysis. The prediction, that

361 MLID would be more common in fossil forms than in recent ones, is not supported. Recent

362 Bornean orangutans are more affected than any fossil taxon (except Anapithecus hernyaki

363 from Hungary where all seven teeth from five individuals are affected). 


\section{Island source}

366 There is a major difference in the occurrence of MLID between islands with Bornean

367 orangutans being significantly more affected than Sumatra (Table VII). Recent Sumatran

368 orangutans show much less MLID than do the fossil orangutans from the same island.

369 Indeed, extremes of prevalence are found between the two recent samples from Borneo 370 and Sumatra.

371

372

\section{Discussion}

374 In terms of proximate causation, MLID is more likely due to dental crowding in infancy,

375 rather than genetics, based on the following observations: a) the common occurrence of

376 MLID within and among ape taxa; b) its physical appearance corresponding to the form of

377 the central incisor with which it is so closely located; c) its clear difference in shape from

378 linear enamel hypoplasia; d) prior work which links compromised somatic/skeletal

379 development to crypt fenestration enamel defects (Lukacs 1999; Skinner et al. 2014); and,

380 finally, e) the dissimilarity of MLID to examples of genetic defects such as amelogenesis

381 imperfecta (Hart et al. 2003; Lygidakis and Lindenbaum 1987). We found that: a) MLID is

382 more common in males; b) tooth size has only a mild, statistically non-significant effect on

383 MLID; c) MLID is significantly more common in Bornean orangutans and least common in

384 those from Sumatra, with most fossil assemblages showing intermediate prevalence

385 between these two extremes. 
387 In our explanatory model, inter-crypt fenestration is a necessary but not sufficient

388 explanation for MLID. While we have shown that inter-crypt fenestration occurs, we do not

389 know how common this phenomenon is. Inter-crypt fenestrae have been described

390 between crowded, unerupted $\mathrm{I}^{2}, \mathrm{C}$ and $\mathrm{P}^{3}$ in a juvenile gorilla from the Osmond Hill

391 Collection (Royal College of Surgeons) (Beynon et al. 1991). Nothing is known of the

392 developmental health or conditions of this animal.

393

394 Our micro-morphological analysis, which is limited to the outer enamel surface, shows

395 exposed Tomes' process pits in the floor of the defect. We conclude that matrix secretion

396 ceased abruptly without recovery of function, at least centrally within the defect. At the

397 time, the affected ameloblasts still possessed the distal portion of their Tomes' processes

398 (Witzel et al. 2008). We infer that, in terms of etiology, the proximate causative agent was a

399 short-term event affecting a localized group of cells. This scenario is compatible with a

400 sudden breaching of the inter-crypt septum creating a fenestration. Rather than invoking a

401 gradual compression of a tooth crown within an unyielding crypt - a physical process that

402 would have been detectable as a graduated secretory response from the ameloblast - it

403 seems more likely, given the ledge-like appearance of many of the MLIDs, that there was

404 relatively abrupt abnormal contact of the developing crown with the sharp edge of a crypt

405 fenestration. Histological thin sections of original teeth with MLID will be required to 406 resolve these speculations.

407

408 It is surprising that MLID, which we consider a crowding defect, is little if at all affected by

409 tooth size. There is a non-significant tendency for teeth with the defect to be slightly bigger 
410 in most comparisons (Table IV); larger samples in future studies may confirm this trend.

411 Another crypt fenestration defect (LHPC) is more severe in bigger primary teeth from

412 infant apes (Skinner and Newell 2003). On current evidence, the preponderance of MLID in

413 male orangutans is not due to sexual dimorphism in tooth size. Rather, we think that MLID

414 is due to undergrowth of the upper jaw in the presence of anterior teeth whose sizes are

415 more tightly genetically controlled and less susceptible to epigenetic perturbation than is

416 bone formation in the maxilla and premaxilla (Lukacs 1999).

418 We found that fossil orangutans from Sumatra show significantly more MLIDs than do

419 recent Sumatran orangutans and that they show the same proportion of MLID as do

420 Bornean orangutans. There are two possible explanations for this observation. Anatomical

421 factors predisposing to MLID, due to shared genetic heritage between southern Sumatran

422 and Bornean orangutans (Nater et al. 2011), may over-ride island differences in habitat

423 quality. Alternatively, the quality of the habitat, in terms of developmental stress leading to

424 anterior tooth crowding, does not differ between Late Pleistocene Sumatra and recent

425 Borneo. We are not in a position to speculate on what might have changed in the habitat

426 between the Pleistocene and recent times in Sumatra beyond noting that the documented

427 demographic decline of Sumatran orangutans must, all else being equal, reduce

428 competition for nutritional resources among conspecifics. The high occurrence of MLID in

429 Late Pleistocene paleo-orangutans from southern Sumatra points to a need for further

430 research to separate the effects of mortality selection in fossil assemblages from a harsher

431 Pleistocene environment, both of which factors can be expected to increase the occurrence 432 of MLID. 
434 We observed the highest prevalence of MLID in Anapithecus from Rudabanya, Hungary 435 among whom all five individual Anapithecus show one or both incisors with the defect. This 436 is the highest prevalence noted so far in any taxon and raises the possibility of marked 437 developmental stress related to nutrition and/or disease in some members of this taxon. 438 Such a conclusion is not incompatible with the inference that Rudabanya is a prime habitat

439 for Anapithecus (Andrews and Cameron 2010) since this is a mortality cohort possibly 440 created by predation of more vulnerable individuals in a primate troop (Kordos and Begun

441 2002). The presence of MLID in a pliopithecoid raises the strong likelihood that this

442 inferred form of dental crowding will be present in some Old World monkeys as well.

444 Recent evidence, based on the periodicity of repetitive linear enamel hypoplasia, suggests

445 that Bornean orangutans show a preponderance of semi-annual stress episodes, in contrast 446 to Sumatran orangutans, who showed mostly annual cycles (Skinner 2014). This difference

447 was interpreted as providing mild support for the notion of better habitat quality in

448 Sumatra (Skinner 2014). This contrasts with an earlier effort to compare postnatal

449 developmental stress in orangutans, which found no difference between the islands in the 450 prevalence of localized hypoplasia of the primary canine (LHPC), thought to be a marker of 451 bone thinning in infancy (Skinner and Newell 2003). However, LHPC occurs in the first few 452 months after birth while formation of the upper lateral permanent incisor crown spans 453 about age two to six years (Beynon et al. 1991). Hence, a crowding defect of enamel 454 formation (i.e., MLID) that occurs during the developmental life stage from full reliance on 455 breast milk to growing independent foraging by the infant orangutan (van Noordwijk et al. 
456 2013) could be a useful marker of comparative developmental stress between island taxa

457 and more suitable than LHPC to examine ideas about differences in habitat quality. 458

459 MLID is much more common in males, and in recent orangutans from Borneo. These two 460 observations may be linked. In terms of craniofacial dimensions, male Bornean infant 461 orangutans may be up to $20 \%$ larger than females (Hens 2005). Extrapolating this 462 observation to nutritional need suggests that lactation demands from a male infant 463 orangutan are greater (but see van Noordwijk et al (2013)). Human mothers of male 464 infants can produce milk that has 25\% greater energy content (Powe et al. 2010). Such an 465 adaptation, to respond to greater nutritional demand from male infants, might indicate that 466 male infant orangutans are more prone to developmental dental crowding under

467 conditions of relative food stress (as seems to pertain in Borneo (Knott 1998)).

468 Alternatively, rather than invoking a sex difference in metabolic requirements, there may

469 be sex differences in the ontogenetic acquisition of skilled foraging behaviors (Russon

470 2006). Also, rather than arguing for differences in just habitat quality between the islands,

471 it may be germane that lactation, which presumably provides a reasonably assured

472 component of the infant's food requirements, is significantly longer in Sumatran than 473 Bornean orangutans (van Noordwijk et al. 2013).

\section{Conclusion}

477 We examined the form and prevalence of an unusual defect of dental formation, observable 478 on the mesio-labial surface of the maxillary lateral incisor (MLID) of apes, that we think has 
479 the potential to be a marker of compromised infant development and, by inference, habitat 480 quality. Our micro-CT scans and radiography combined with scanning electron microscopy

481 of enamel surfaces show inter-crypt fenestration, predisposing the unerupted lateral 482 incisor to direct 'tooth-to-tooth' or 'tooth-to-fenestrated crypt edge' contact with the 483 creation of abnormal enamel surfaces including pits, plane-form and ledge defects. Neither 484 lateral incisor crown size specifically, nor size of the anterior dentition generally, including 485 sexually dimorphic canine teeth, links to MLID. We conclude that undergrowth of the jaws, 486 not tooth size, is the major predisposing cause of the defect. There is more of a difference in 487 MLID occurrence between islands than between sexes. MLID is significantly more common 488 in Bornean orangutan individuals than in Sumatra, with males more affected than females.

489 We conclude that the better nutritional environment for growing apes in Sumatra 490 promotes more optimal jaw growth protecting them from MLID. Surprisingly, paleo491 orangutans from southern Sumatra are significantly more affected by MLID than are recent 492 (northern) Sumatran orangutans, not differing in this respect from Bornean orangutans.

493 Finally, given the generally high prevalence of this dental crowding defect in Bornean and 494 fossil orangutans spread from Vietnam to Sumatra, we conclude that the optimal 495 developmental environment for recent orangutans, currently prevailing in northern 496 Sumatra, is not typical of the broad spatio-temporal habitats of orangutans in the past. 497 Thus, while MLID can be proposed as a proxy for habitat quality among apes, its overall 498 utility may be limited to the detection of optimal habitats only. 
501 MFS acknowledges helpful discussions or assistance from Heather Edgar, David Hopwood,

502 Paul Klassen, Laszlo Kordos, Meg Stark, Vu The Long, and Ji Xueping. DLH would like to

503 thank Linda Gordon and Richard Thorington, Department of Mammals, Smithsonian

504 National Museum and Natural History for access to specimens, catalog records, field notes,

505 and facilities and the University of Oregon Graduate Student Research Award program for

506 financial support. For access to specimens for CT scanning we thank Thomas Koppe and

507 the Greifswald Anatomy Museum, Germany. This research was supported by the Max

508 Planck Society, National Science Foundation (SBR-9815546), the Wenner-Gren Foundation,

509 and the Leakey Foundation. Lastly, we are grateful to the editor and two anonymous

510 reviewers for their patience and excellent advice.

511

512 References

513

514 Altmann, S. A. (1998). Foraging for survival: Yearling baboons in Africa. Chicago: The

515

516

517

518

519

520

521

522

523

524

525

526

527

528

529

530

531

532

533 University of Chicago Press.

Andrews, P., \& Cameron, D. (2010). Rudabanya: taphonomic analysis of a fossil hominid site from Hungary. Palaeogeography Palaeoclimatology Palaeoecology, 297, 311-329.

Badgley, C., Qi, G., G., Chen, W., W., \& Han, D. D. (1988). Paleoecology of a Miocene, tropical upland fauna : Lufeng, China National Geographic Research, 4(2), 178-195.

Begun, D. R., Nargolwalla, M. C., \& Hutchinson, M. P. (2006). Primate diversity in the Pannonian Basin: In situ evolution, dispersals or both? Beitrage zur Paläontologie, 30, 43-56.

Beynon, A. D., Dean, M. C., \& Reid, D. J. (1991). Histological study on the chronology of the developing dentition in Gorilla and Orangutan. American Journal of Physical Anthropology, 86, 189-203.

Boughner, J. C., \& Dean, M. C. (2004). Does space in the jaw influence the timing of molar crown initiation? A model using baboons (Papio anubis) and great apes (Pan troglodytes, Pan paniscus). Journal of Human Evolution, 46, 255-277.

Delgado, J., Roberto A. , \& van Schaik, C. P. (2000). The behavioral ecology and conservation of the Orangutan (Pongo pygmaeus): A tale of two islands. Evolutionary Anthropology, 201-218.

DeWitte, S. N., \& Stojanowski, C. M. (2015). The osteological paradox 20 years later: past perspectives, future directions. Journal of Archaeological Research, 23, 397-450. 
534

535

536

537

538

539

540

541

542

543

544

545

546

547

548

549

550

551

552

553

554

555

556

557

558

559

560

561

562

563

564

565

566

567

568

569

570

571

572

573

574

575

576

577

578

579
DiOrio, L. P., Miller, S. A., \& Navia, J. M. (1973). The separate effects of protein and calorie malnutrition on the development and growth of rat bones and teeth. The Journal of Nutrition, 103, 856-865.

Drawhorn, G. M. (1994). The systematics and paleodemography of fossil orangutans (Genus Pongo). Doctoral, University of California, Davis, Davis.

Dressino, V., \& Pucciarelli, H. M. (1997). Cranial growth in Saimiri sciureus (Cebidae) and its alteration by nutritional factors: A longitudinal study. American Journal of Physical Anthropology, 102, 545-554.

Garat, J. A., Martin, A. E., Pani, M., Holgado, N. R., Meheris, H. E., \& Gonzalez, S. (2007). Orthodontic implications of protein undernutrition in mandibular growth. A cephalometric study in growing rats. Acta Odontologica Latinoamericana, 20(2), 7378.

Hanebuth, T., Karl, S., \& Grootes, P. M. (2000). Rapid flooding of the Sunda Shelf: A late glacial sea-level record. Science, 288, 1033-1035.

Hannibal, D. L. (2003). An unusual hypoplastic defect of the maxillary lateral incisors in great apes. [Abstract]. American Journal of Physical Anthropology, Annual Meeting Issue (Supplement 36), 108-109.

Harrison, T. (2010). Apes among the tangled branches of human origins. Science, 327, 532534.

Harrison, T., Krigbaum, J., \& Manser, J. (2006). Primate biogeography and ecology on the Sunda Islands: Paleontological and Zooarchaeological perspectives. In S. M. Lehman, \& J. G. Fleagle (Eds.), Primate Biogeography (pp. 331-372): Springer.

Hart, T. C., Hart, P. S., Gorry, M. C., Michalec, M. D., Ryu, O. H., Uygur, C., et al. (2003). Novel ENAM mutation responsible for autosomal recessive amelogenesis imperfecta and localized enamel defects. Journal of Medical Genetics, 40, 900-906.

Hens, S. M. (2005). Ontogeny of craniofacial sexual dimorphism in the orangutan (Pongo pygmaeus). I: Face and palate. American Journal of Primatology, 65, 149-166.

Hillson, S. (1996). Dental Anthropology. Cambridge: Cambridge University Press.

Husson, S. J., Wich, S. A., Marshall, A. J., Dennis, R. D., Ancrenaz, M., Brassey, R., et al. (2009). Orangutan distribution, density, abundance and impacts of disturbance. In S. A. Wich, A. S. S. Utami, S. T. Mitra, \& C. P. van Schaik (Eds.), Orangutans: Geographical variation in behavioral ecology and conservation (pp. 77-96). Oxford: Oxford University Press.

IBM (2013). SPSSStatistics22. IBM.

Ibrahim, Y. K., Tshen, L. T., Westaway, K. E., Cranbrook, E. O., Humphrey, L., Muhammad, R. F., et al. (2013). First discovery of Pleistocene orangutan (Pongo sp.) fossils in Peninsular Malaysia: Biogeographic and paleoenvironmental implications. Journal of Human Evolution, 65, 770-797.

Knott, C. D. (1998). Changes in orangutan caloric intake, energy balance, and ketones in response to fluctuating fruit availability. International Journal of Primatology, 19(6), 1061-1079.

Kordos, L., \& Begun, D. R. (2001). Primates from Rudabanya: allocation of specimens to individuals, sex and age categories. Journal of Human Evolution, 40, 17-39.

Kordos, L., \& Begun, D. R. (2002). Rudabanya: A late Miocene subtropical swamp deposit with evidence of the orgin of the African apes and humans Evolutionary Anthropology, 11, 45-57. 
580

581

582

583

584

585

586

587

588

589

590

591

592

593

594

595

596

597

598

599

600

601

602

603

604

605

606

607

608

609

610

611

612

613

614

615

616

617

618

619

620

621

622

623

624
Louys, J. (2012). Mammal community structure of Sundanese fossil assemblages from the Late Pleistocene, and a discussion on the ecological effects of the Toba eruption. Quaternary International, 258, 80-87.

Louys, J., \& Meijaard, E. (2010). Palaeoecology of Southeast Asian megafauna-bearing sites from the Pleistocene and a review of environmental changes in the region. Journal of Biogeography, 37, 1432-1449, doi:DOI: 10.1111/j.1365-2699.2010.02297.x.

Lukacs, J. R. (1999). Interproximal contact hypoplasia in primary teeth: a new enamel defect with anthropological and clinical significance. American Journal of Human Biology, 11, 718-734.

Luke, D. A., Tonge, C. H., \& Reid, D. J. (1979). Metrical analysis of growth changes in the jaws and teeth of normal, protein deficient and calorie deficient pigs. Journal of Anatomy, 129(3), 449-457.

Lygidakis, N. A., \& Lindenbaum, R. H. (1987). Pitted enamel hypoplasia in tuberous sclerosis patients and first -degree relatives. Clinical Genetics, 32, 216-221.

McCance, R. A., \& Ford, E. H. R. (1961). Severe undernutrtion in growing and adult animals. 7. Development of the skull, jaws and teeth in pigs. British Journal of Nutrition, 15, 211-224.

Meijaard, E. (2003). Mammals of south-east Asian islands and their Late Pleistocene environments. Journal of Biogeography, 30, 1245-1257.

Meiri , S., Meijaard, E., Wich, S. A., Groves, C. P., \& Helgen, K. M. (2008). Mammals of Borneosmall size on a large island. Journal of Biogeography, 35, 1087-1094.

Morrogh-Bernard, H. C., Husson, S. J., Knott, C. D., Wich, S. A., van Schaik, C. P., van Noordwijk, M. A., et al. (2009). Orangutan activity budgets and diet. A comparison between species, populations and habitats. In S. A. Wich, A. S. S. Utami, S. T. Mitra, \& C. P. van Schaik (Eds.), Orangutans: Geographical variation in behavioral ecology and conservation (pp. 119-133). Oxford: Oxford University Press.

Nargolwalla, M. C., Begun, D. R., Dean, M. C., Reid, D. J., \& Kordos, L. (2005). Dental development and life history in Anapithecus hernyaki. Journal of Human Evolution, 49, 99-121.

Nater, A., Nietlisbach, P., Arora, N., van Schaik, C. P., van Noordwijk, M. A., Willems, E. P., et al. (2011). Sex-biased dispersal and volcanic activities shaped phylogeographic patterns of extant orangutans (genus: Pongo). Molecular Biology and Evolution, 28(8), 2275-2288, doi:10.1093/molbev/msr042.

Pinto-Cisternas, J., Moggi-Cecchi, J., \& Pacciani, E. (1995). A morphological variant of the permanent upper lateral incisor in two Tuscan samples from different periods. In J. Moggi-Cecchi (Ed.), Aspects of dental biology: palaeontology, anthropology and evolution (pp. 333-339). Florence: International Institute for the Study of Man.

Powe, C. E., Knott, C. D., \& Conklin-Brittain, N. L. (2010). Infant sex predicts breast milk energy content. American Journal of Human Biology, 22, 50-54.

Qi, G., Dong, W., Zheng, L., Zhao, L., Gao, F., Yue, L., et al. (2006). Taxonomy, age and environmental status of the Yuanmou hominoids. Chinese Science Bulletin, 51(6), 704-712.

Russon, A. E. (2006). Acquisition of complex foraging skills in juvenile and adolescent orangutans (Pongo pygmaeus): developmental influences. Aquatic Mammals, 32, 500-510. 
Russon, A. E., Wich, S. A., Ancrenaz, M., Kanamori, T., Knott, C. D., Kuze, N., et al. (2009). Geographic variation in orangutan diets. In S. A. Wich, A. S. S. Utami, S. T. Mitra, \& C. P. van Schaik (Eds.), Orangutans: Geographical variation in behavioral ecology and conservation (pp. 135-156). Oxford Oxford University Press.

Skinner, M. F. (1986). An enigmatic hypoplastic defect of the deciduous canine. American Journal of Physical Anthropology, 69: 59-69.

Skinner, M. F. (2000). A re-evaluation of localized hypoplasia of the primary canine as a marker of craniofacial osteopenia in European Upper Paleolithic infants. Acta Universitatis Carolinae Medica, 41, 41-58.

Skinner, M. F., Hadaway, W., \& Dickie, J. (1994). Effects of ethnicity, nutrition and birth month on localized enamel hypoplasia of the primary canine. Journal of Dentistry for Children, 61, 109-113.

Skinner, M. F., \& Hung, J. T. W. (1989). Social and biological correlates of localized enamel hypoplasia of the human deciduous canine tooth. American Journal of Physical Anthropology, 79: 159-175.

Skinner, M. F., \& Newell, E. A. (2003). Localised hypoplasia of the primary canine in bonobos, orangutans and gibbons. American Journal of Physical Anthropology, 120, 61-72.

Skinner, M. F., Rodrigues, A. T., \& Byra, C. (2014). Developing a pig model for crypt fenestration-induced localized hypoplastic enamel defects in humans. American Journal of Physical Anthropology, 154, 239-250.

Smith, T. M., Bacon, A.-M., Demeter, F., Kullmer, O., Nguyen, K. T., de Vos, J., et al. (2011). Dental tissue proportions in fossil orangutans from Mainland Asia and Indonesia. Human Origins Research, 1:e1, 1-6.

Thomaz, E. B. A. F., Cangussu, M. C. T., da Silva, A. A. M., \& Assis, A. M. O. (2010). Is malnutrition associated with crowding in permanent dentition? International Journal of Environmental Research and Public Health, 7, 3531-3544.

Tonge, C. H., \& McCance, R. A. (1973). Normal development of the jaws and teeth in pigs, and the delay and malocclusion produced by calorie deficiencies. Journal of Anatomy, 115, 1-22.

van Noordwijk, M. A., Willems, E. P., Atmoko, S. S. U., Kuzawa, C. W., \& van Schaik, C. P. (2013). Multi-year lactation and its consequences in Bornean orangutans (Pongo pygmaeus wurmbii). Behavioral Ecology and Sociobiology, 67, 805-814, doi:DOI 10.1007/s00265-013-1504-y.

van Schaik, C. P., Marshall, A. J., \& Wich, S. A. (2009). Geographic variation in orangutan behavior and biology. Its functional interpretation and its mechanistic basis. In S. A. Wich, A. S. S. Utami, S. T. Mitra, \& C. P. van Schaik (Eds.), Orangutans: Geographical variation in behavioral ecology and conservation (pp. 351-361). Oxford: Oxford University Press.

Wich, S. A., Meijaard, E., Marshall, A. J., Husson, S. J., Ancrenaz, M., Lacy, R. C., et al. (2008). Distribution and conservation status of the orangutan (Pongo spp) on Borneo and Sumatra: How many remain? Oryx, 42(3), 329-339.

Wich, S. A., Vogel, E. R., Larsen, M. D., Fredricksson, G. M., Leighton, M., Yeager, C. P., et al. (2011). Forest fruit production is higher on Sumatra than on Borneo. PLoS Biology, 6(6), 1-9 e21278. 
670 Wilting, A., Sollmann, R., Meijaard, E., Helgen, K. M., \& Fickel, J. (2012). Mentawai's endemic, 671 relictual fauna: is it evidence for Pleistocene extinctions on Sumatra? Journal of Biogeography, 39(9), 1608-1620, doi:doi:10.1111/j.1365-2699.2012.02717.x. Histological analysis of abnormal enamel microstructure associated with hypoplastic enamel defects in human teeth. American Journal of Physical Anthropology, 136, 400-414.

Wood, J. W., Milner, G. R., Harpending, H. C., \& Weiss, K. M. (1992). The osteological paradox: Problems of inferring prehistoric health from skeletal samples. Current Anthropology, 33, 343-370.

Zhao, L., Lu, C., \& Zhang, W. (2008). Age at first molar eruption in Lufengpithecus lufengensis and its implications for life-history evolution. Journal of Human Evolution, 54(2), 251-257.

Zihlman, A. L., Bolter, D. R., \& Boesch, C. (2007). Skeletal and dental growth and development in chimpanzees of the Taï National Park, Côte D'Ivoire. Journal of Zoology, 273, 63-73.

686

687 


\section{Figure Legends}

689

690 Fig. 1. Labial view of right maxillary lateral incisor (cast) with defect (MLID). This example

691 shows a commonly observed form with a diagonal notch (indicated by black line),

692 encroaching onto the root (Tooth 107-44b, paleo-Sumatran orangutan 11484-L2, Lida Ajer 693 Cave).

694

695 Fig. 2. Source of museum specimens of orangutans where provenience within islands is 696 known.

697

698 Fig. 3. Radiographs of the maxillary incisor region of two, younger and older, infant

699 chimpanzees: A. female M475, m2 root apex open; B. male M173, m2 root apex closed. Note 700 visual superimposition of the less mineralized/formed lateral incisor crown and incisal

701 edge and crypt wall of the more mineralized/formed central incisor crown.

702

703 Fig. 4. 3D reconstruction from micro-CT scan of unerupted incisors in orangutan infant

704 UGAZ 14.5.8 with completed milk dentition showing the relationship of the permanent

705 maxillary incisors during crown formation and fenestrated inter-crypt septa (top right

706 panel). Note superimposition of the incisal edge of the central incisor on the mid-crown

707 region of the lateral incisor crown (bottom left panel).

708

709 Fig. 5. Variation in size and shape of the developmental dental defect in maxillary lateral

710 incisors (casts) in a variety of primates. Specimens are turned so the defect is orthogonal

711 to the viewer. Most north-south measures (in $\mathrm{mm}$ ) are single profiles taken through the 
712 deepest part of a defect (in microns) (except where noted). The rectangular area

713 demarcated in 'A' is reproduced in Figure 6. A. 107-42b: paleo-Sumatran orangutan 11485-

714 L48, Lida Ajer Cave, left; B. 107-43b: paleo-Sumatran orangutan 11484-L11, Lida Ajer Cave,

715 right; C. 107-44b: paleo-Sumatran orangutan 11484-L2, Lida Ajer Cave, right; D. 107-45b:

716 paleo-Sumatran orangutan 11488-44, left, mean profile across defect width is shown; E.

717 165b: siamang 11670-1, left; F. 130: Rud 97 Anapithecus hernyaki A.7, Loc.II 1989, left; G.

718 314: Lufengpithecus lufengensis YV622, left.

719

720 Fig. 6: Scanning electron microscope images of a cast in araldite of a paleo-orangutan left

721 upper lateral incisor 11485-L48, Lida Ajer Cave, Sumatra. A. Example of enamel hypoplasia

722 pit that is not a maxillary lateral incisor defect (MLID); note little worn Tomes' process pits

$723(\star)$ within the sequestered surface of defect on left side of panel, indicating premature,

724 abnormal cessation of secretion by enamel-forming cells. B. Close up of deepest part of an

725 MLID showing the floor of the defect on the left and shoulder of defect on the right. Faint

726 ridges on the shoulder on the right side of panel represent normal enamel increments

727 called perikymata (dashed arrows). MLID contours of floor and shoulder do not conform to

728 normal enamel internal structure. C. Floor of MLID showing abnormal exposure of

729 somewhat worn Tomes' process pits ( $\star$ ) (enamel surface exposed to normal wear). D. Low

730 power overview of MLID; root to left side of panel, cervical part of enamel crown on right

731 side of panel. This example is large. Bubble artifacts in the deepest part of the defect can

732 also be seen in panel B. E. Junction of floor of defect with slope of the shoulder (on right).

733 On the left side, the floor of the defect is obscured by foreign matter that has been partially

734 cleaned out (see groove on upper right). F. Junction of root (left) surface with enamel 
735 (right); both are normal in appearance. G. Floor of defect with faintly visible, worn Tomes'

736 process pits on upper left obscured, on lower and right sides, by a layer of foreign matter.

737 H. Normal, worn labial enamel.

738 


\section{MLID Tables with Headings-26Aug16}

Table I. Sample of extant orangutans examined for MLID

\begin{tabular}{cllll}
\hline Island & Male & Female & Sex unknown & Total \\
\hline Borneo & 16 & 30 & 3 & 49 \\
Sumatra & 13 & 7 & 1 & 21 \\
Total & 29 & 37 & 4 & 70 \\
\hline
\end{tabular}

Table II. Sample of fossil hominoid lateral incisors examined for MLID

\begin{tabular}{|c|c|c|c|c|}
\hline Taxon & $\mathrm{N}$ & $\begin{array}{l}\text { Minimum } \\
\text { number of } \\
\text { individuals }\end{array}$ & Source & Date \\
\hline Anapithecus hernyaki & 7 & 5 & A & $\mathrm{MN} 9,11.2-9.7 \mathrm{Ma}^{1}$ \\
\hline Lufengpithecus lufengensis & 2 & 2 & B & Late Miocene, $7 \mathrm{Ma}^{2}$ \\
\hline Paleo-orangutan Vietnam total & 11 & 10 & $\mathrm{C}$ & \\
\hline Dieu Cave & 1 & & & undated Pleistocene \\
\hline Hang Hum & 1 & & & $140-80 K^{3}$, end Pleistocene ${ }^{4}$ \\
\hline Hoa Binh & 1 & & & undated Pleistocene ${ }^{5}$ \\
\hline Lang Trang & 7 & & & $150 \mathrm{~K}^{6}$, Mid-Pleistocene $^{7}, 80-60 \mathrm{~K}^{8}$ \\
\hline Tham Om & 1 & & & $250-140 \mathrm{~K}^{3}$, Late Pleistocene ${ }^{4}$ \\
\hline Paleo-orangutan Sumatra total & 56 & 38 & $\mathrm{D}$ & \\
\hline Djamboe & 5 & & & $56-85 \mathrm{~K}^{9}, 60-70 \mathrm{~K}^{11}$, Early Hol ${ }^{12}$ \\
\hline Sibrambang & 22 & & & Pleist./Holo. ${ }^{9}, 128-118 \mathrm{~K}^{10,13}, 80 \mathrm{~K}^{13}$ \\
\hline Lida Ajer & 19 & & & $>80 \mathrm{~K}^{9,11}$, IS. $5 \mathrm{e}^{7,13}$, Early Hol ${ }^{12}$ \\
\hline Unspecified & 10 & & & \\
\hline Total & 76 & & & \\
\hline
\end{tabular}

Source: A. Geological Museum Budapest; B. Zoological Institute, Kunming; C. Institute of Archaeology, Hanoi; D. Naturalis, Leiden

Dating references: 1. Begun et al. 2006 (MNI also based on this article); 2. Ho 1985; 3. Bacon et al. 2006; 4. Harrison 2000; 5. Bacon and Long 2001; 6. Jon de Vos (pers. comm.); 7. (Long et al. 1996); 8. Bacon et al. 2004; 9. Drawhorn 1994-Lida Ajer dates from ${ }^{18} \mathrm{O}$ Stage $4>71 \mathrm{~K} ; 10$. de Vos 1983; 11. van den Bergh et al. 1996; 12. Harrison et al. 2006; 13. Louys 2011 
Table III. Sex differences in MLID expression in recent orangutan samples

\begin{tabular}{llllllll}
\hline Sample & Sex & Comparison & $\mathrm{N}$ & Yes/No & \% Yes & Chi Square $^{1}$ & $\mathrm{P}$ \\
\hline Borneo & Male & Teeth & 29 & $27 / 2$ & 93.1 & & \\
& Female & Teeth & 53 & $32 / 21$ & 60.4 & 9.947 & 0.002 \\
& & & & & & & \\
& Male & Individuals & 16 & $15 / 1$ & 93.8 & & \\
& Female & Individuals & 30 & $18 / 12$ & 60.0 & 5.863 & 0.015 \\
Sumatra & Male & Teeth & 23 & $8 / 15$ & 34.8 & & \\
& Female & Teeth & 14 & $2 / 12$ & 14.3 & 1.854 & 0.173 \\
& & & & & & & \\
& Male & Individuals & 13 & $5 / 8$ & 38.5 & & \multirow{2}{*}{0.260} \\
\hline
\end{tabular}

1. Fisher's Exact Tests were run on all comparisons above (as some groups had less than five cases) and yielded identical patterns of significance.

Table IV. Comparison of tooth size ${ }^{1}$ from extant orangutans with and without MLID.

\begin{tabular}{llllllllll}
\hline Tooth & Measure & \multicolumn{2}{c}{ With MLID } & \multicolumn{2}{c}{ Without MLID } & \multicolumn{2}{c}{ Student's } & \multicolumn{2}{c}{ Mann-Whitney } \\
& & $\mathrm{N}$ & Mean & $\mathrm{N}$ & Mean & ' $\mathrm{t}$ ' & $\mathrm{P}$ & Value & $\mathrm{P}$ \\
\hline Central & Mesio-distal & 6 & 0.0874 & 17 & -.0309 & 0.262 & 0.796 & -0.140 & 0.889 \\
incisor & Labio-lingual & 6 & 0.0970 & 16 & -0.0364 & 0.294 & 0.772 & -0.295 & 0.768 \\
& Crown height & 5 & 0.4624 & 13 & -0.1778 & 1.375 & 0.188 & -1.626 & 0.104 \\
& Volume & 5 & 0.4288 & 13 & -1.2534 & 1.956 & 0.068 & -1.922 & 0.055 \\
Lateral & Mesio-distal & 8 & -0.0938 & 18 & 0.0417 & -0.334 & 0.741 & -0.444 & 0.657 \\
incisor & Labio-lingual & 8 & 0.1477 & 18 & 0.0656 & 0.434 & 0.674 & -0.444 & 0.657 \\
& Crown height & 8 & 0.1412 & 18 & -0.0628 & 0.504 & 0.619 & -0.722 & 0.470 \\
& Volume & 8 & 0.1537 & 18 & -0.0683 & 0.549 & 0.588 & -0.167 & 0.868 \\
Canine & Mesio-distal & 7 & -0.0941 & 16 & 0.0411 & -0.314 & 0.756 & -0.735 & 0.462 \\
& Labio-lingual & 7 & 0.455 & 16 & -0.1993 & 1.610 & 0.122 & -1.604 & 0.109 \\
& Crown height & 7 & 0.0416 & 15 & -0.0194 & 0.141 & 0.890 & -0.035 & 0.972 \\
& Volume & 7 & 0.1836 & 15 & -0.0857 & 0.626 & 0.538 & -0.458 & 0.647 \\
All & Volume & 5 & 0.3398 & 10 & -0.1699 & 1.054 & 0.311 & -0.980 & 0.327 \\
\hline
\end{tabular}

1. Size is expressed as z-scores (i.e., deviation of a measure from the 'sex plus island' mean for that measure) 
Table V. Dental measures (mm) of upper lateral incisors with and without MLID in Paleo-sumatran, Sumatran and Bornean orangutans

\begin{tabular}{lllllllll}
\hline & \multicolumn{4}{c}{ With MLID } & \multicolumn{3}{c}{ Without MLID } & \multicolumn{2}{c}{ Student's } \\
Measure & $\mathrm{N}$ & Mean & SD & $\mathrm{N}$ & Mean & SD & 't' & $\mathrm{P}$ \\
\hline $\begin{array}{l}\text { Paleo- } \\
\text { sumatran }\end{array}$ & & & & & & & & \\
$\quad$ Mesio-distal & 30 & 8.99 & 1.01 & 11 & 8.96 & 0.76 & 0.097 & 0.923 \\
Labio-lingual & 27 & 9.34 & 1.10 & 11 & 9.20 & 1.03 & 0.366 & 0.717 \\
Crown height & 7 & 12.71 & 1.52 & 8 & 12.38 & 1.19 & 0.484 & 0.637 \\
$\quad$ Volume & 5 & 1109.07 & 326.20 & 3 & 1271.02 & 233.24 & -0.743 & 0.486 \\
Sumatran & & & & & & & & \\
$\quad$ Mesio-distal & 0 & - & - & 10 & 8.27 & 0.96 & N/A & \\
$\quad$ Labio-lingual & 0 & - & - & 10 & 7.87 & 0.54 & N/A & \\
Crown height & 0 & - & - & 10 & 10.30 & 1.54 & N/A & \\
$\quad$ Volume & & & & 10 & 683.17 & 191.01 & N/A & \\
Bornean & & & & & & & & \\
$\quad$ Mesio-distal & 8 & 8.58 & 0.62 & 8 & 8.40 & 0.78 & 0.518 & 0.613 \\
$\quad$ Labio-lingual & 8 & 8.66 & 0.80 & 8 & 8.31 & 0.44 & 1.118 & 0.283 \\
Crown height & 8 & 11.78 & 1.42 & 8 & 11.07 & 1.67 & 0.928 & 0.369 \\
$\quad$ Volume & 8 & 890.44 & 227.11 & 8 & 775.02 & 162.44 & 1.169 & 0.262 \\
\hline
\end{tabular}


Table VI. Frequency of MLID in fossil and recent hominoid upper lateral incisors

\begin{tabular}{|c|c|c|c|c|}
\hline Sample & Side & $\mathrm{N}$ & Yes/No & Affected (\%) \\
\hline \multirow[t]{3}{*}{ L. lufengensis } & Left & 2 & $1 / 1$ & 50.0 \\
\hline & Right & - & & - \\
\hline & Combined & 2 & $1 / 1$ & 50.0 \\
\hline \multirow[t]{3}{*}{ A. hernyaki } & Left & 4 & $4 / 0$ & 100 \\
\hline & Right & 3 & $3 / 0$ & 100 \\
\hline & Combined & 7 & $7 / 0$ & 100 \\
\hline \multicolumn{5}{|l|}{ Paleo-orangutan } \\
\hline \multirow[t]{3}{*}{ Sumatra } & Left & 24 & $16 / 8$ & 66.0 \\
\hline & Right & 32 & $21 / 11$ & 65.6 \\
\hline & Combined & 56 & $37 / 19$ & 66.1 \\
\hline \multirow[t]{3}{*}{ Vietnam } & Left & 8 & $3 / 5$ & 37.5 \\
\hline & Right & 3 & $3 / 0$ & 100 \\
\hline & Combined & 11 & $6 / 5$ & 54.5 \\
\hline \multirow[t]{3}{*}{ All paleo } & Left & 32 & $19 / 13$ & 59.4 \\
\hline & Right & 35 & $24 / 11$ & 68.6 \\
\hline & Combined & 67 & $43 / 24$ & 64.2 \\
\hline \multirow[t]{3}{*}{ Recent Borneo } & Left & 47 & $31 / 16$ & 66.0 \\
\hline & Right & 40 & $30 / 10$ & 75.0 \\
\hline & Combined & 87 & $61 / 26$ & 70.1 \\
\hline \multirow[t]{3}{*}{ Recent Sumatra } & Left & 18 & $5 / 13$ & 27.8 \\
\hline & Right & 20 & $5 / 15$ & 25.0 \\
\hline & Combined & 38 & $10 / 28$ & 26.3 \\
\hline \multirow[t]{3}{*}{ All recent } & Left & 65 & $36 / 29$ & 55.3 \\
\hline & Right & 60 & $35 / 25$ & 58.3 \\
\hline & Combined & 125 & $71 / 54$ & 56.8 \\
\hline
\end{tabular}


Table VII. Distribution of MLID between recent orangutans from Borneo and Sumatra

\begin{tabular}{lllllll}
\hline Comparison & Sample & $\mathrm{N}$ & Yes/No & \% Yes & Chi Square & $\mathrm{P}$ \\
\hline Teeth & Borneo & 87 & $61 / 26$ & 70.1 & & \\
& Sumatra & 38 & $10 / 28$ & 26.3 & 20.68 & $<0.001$ \\
\multirow{4}{*}{ Individual } & Borneo & 49 & $35 / 14$ & 71.4 & & \\
& Sumatra & 21 & $6 / 15$ & 28.6 & 11.13 & $<0.001$ \\
\hline
\end{tabular}




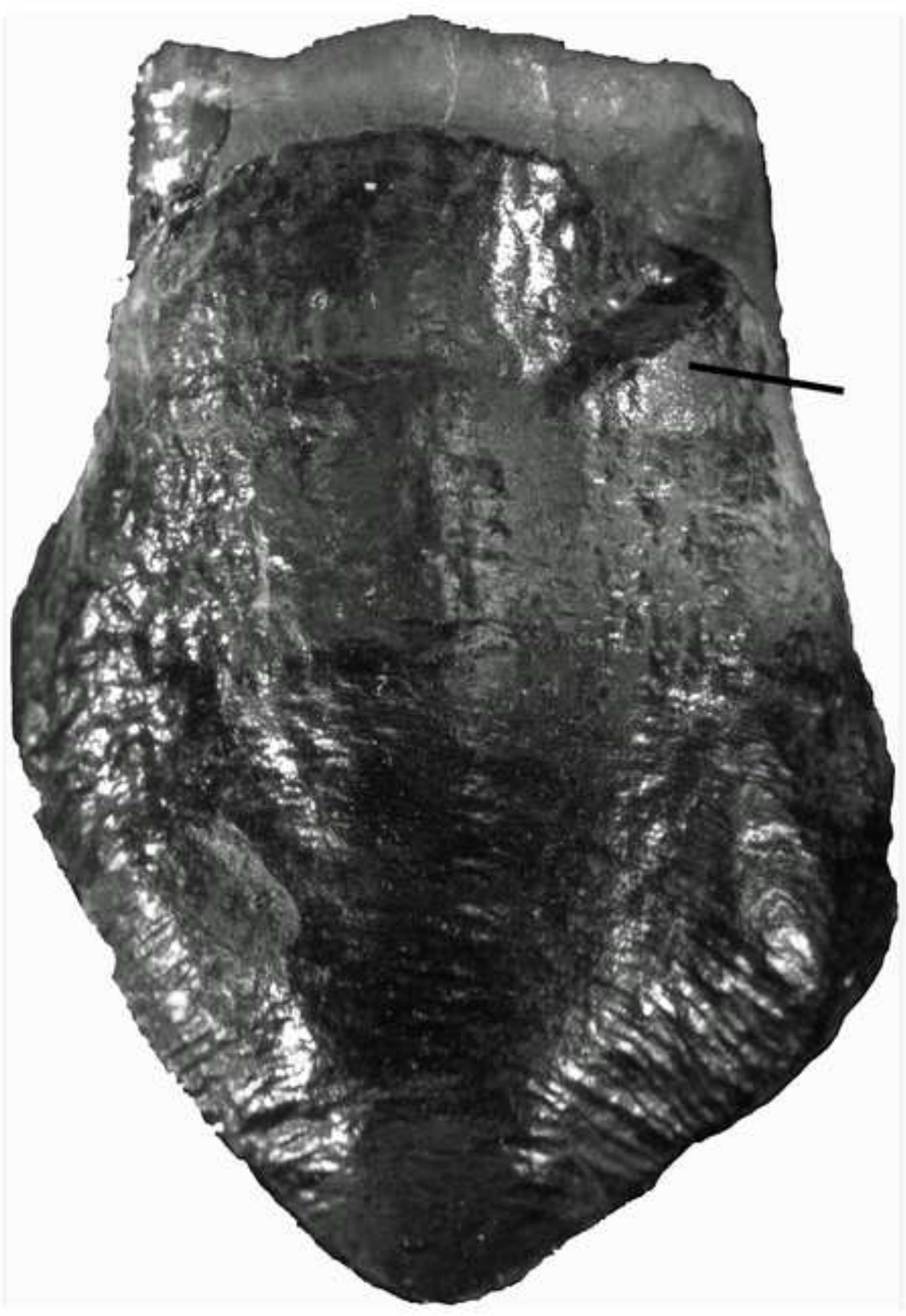




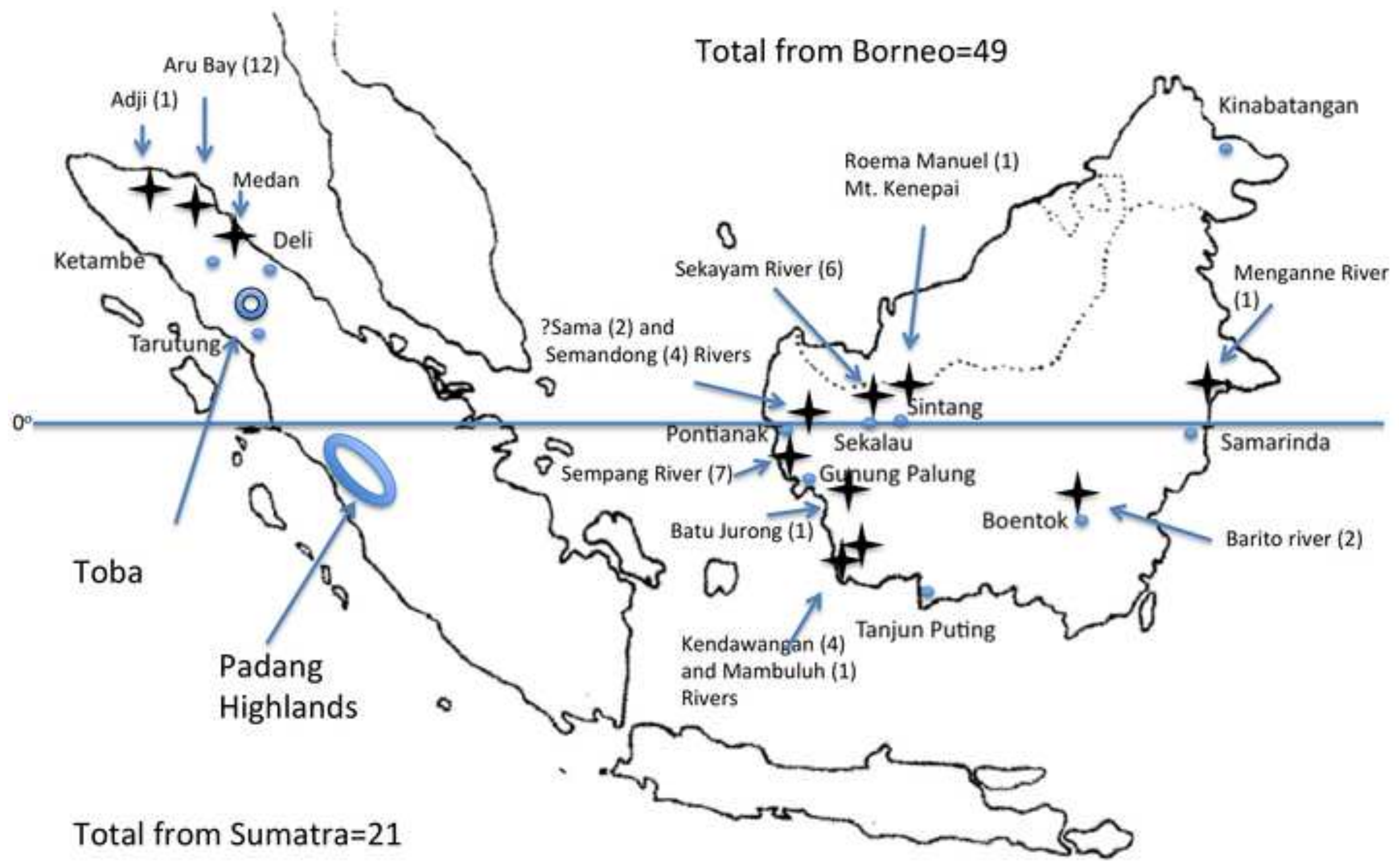

\section{Total from Borneo=49}

River (6)

Sekalau

Gynung Palung

Boentok

D

Kendawangan (4)

and Mambuluh (1)

Rivers 
Central incisor crypt and forming crown
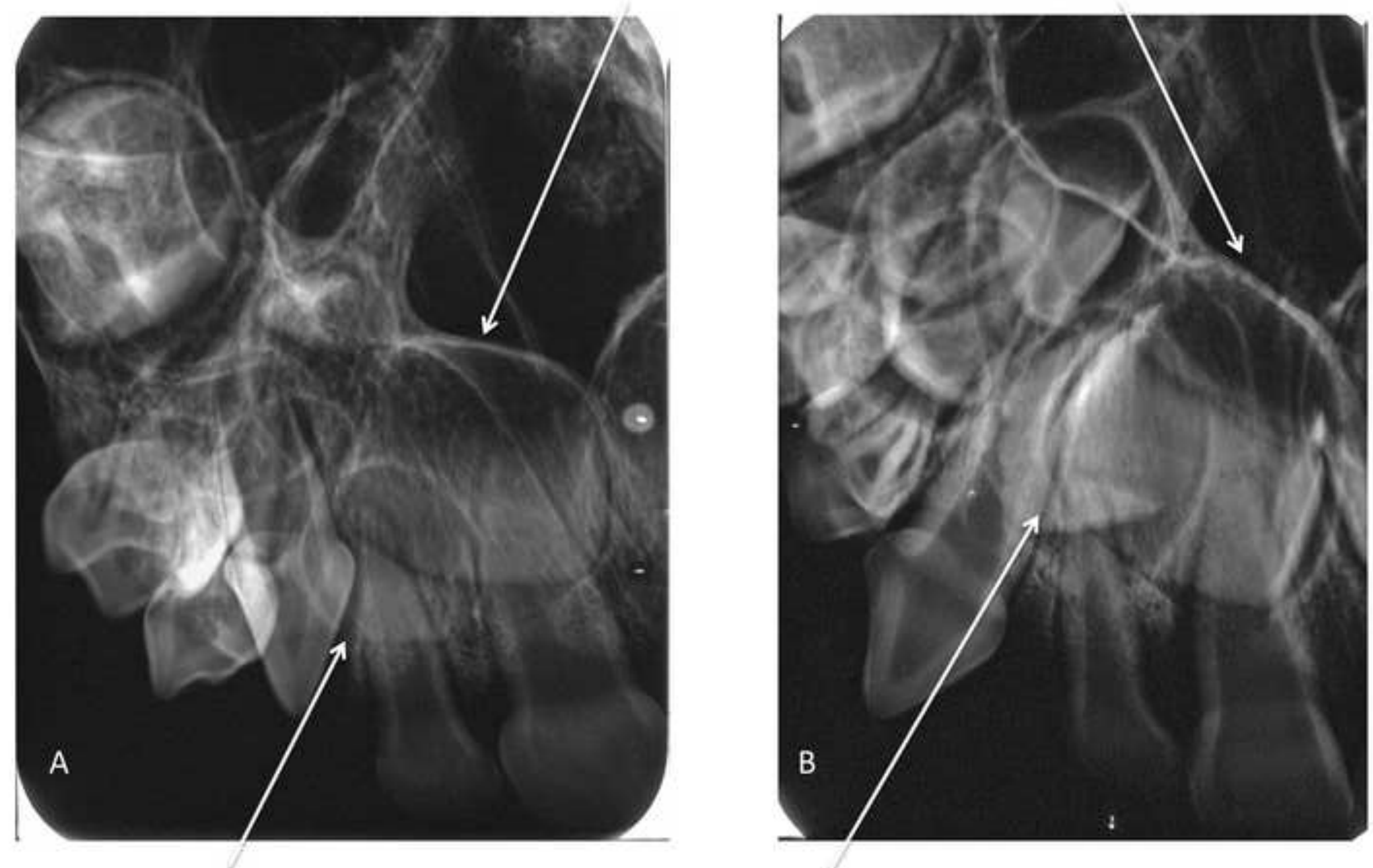

Lateral incisor crypt and less formed crown 


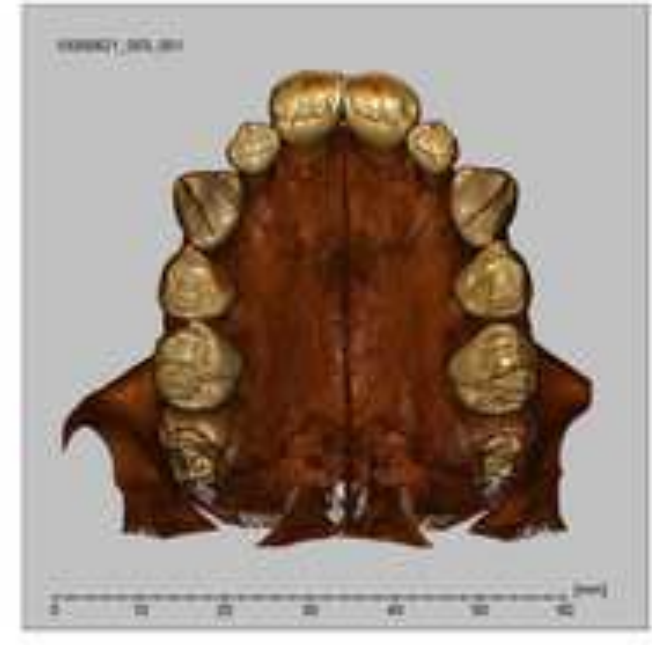

Occlusal of maxilla

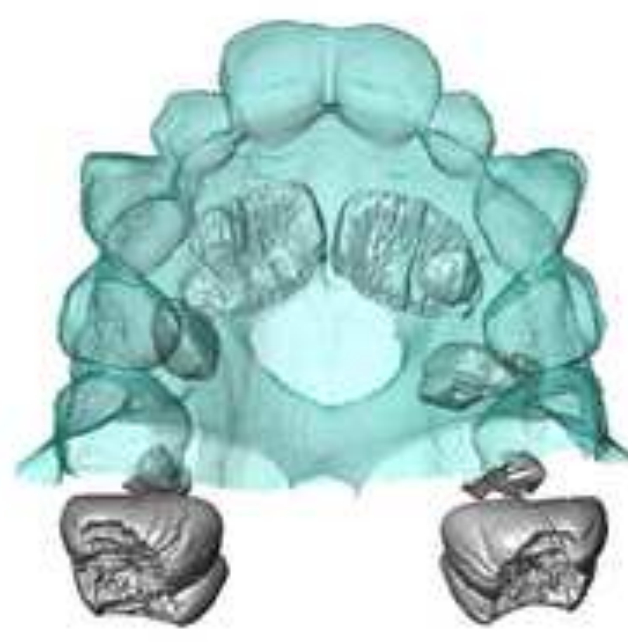

Occlusal of germs

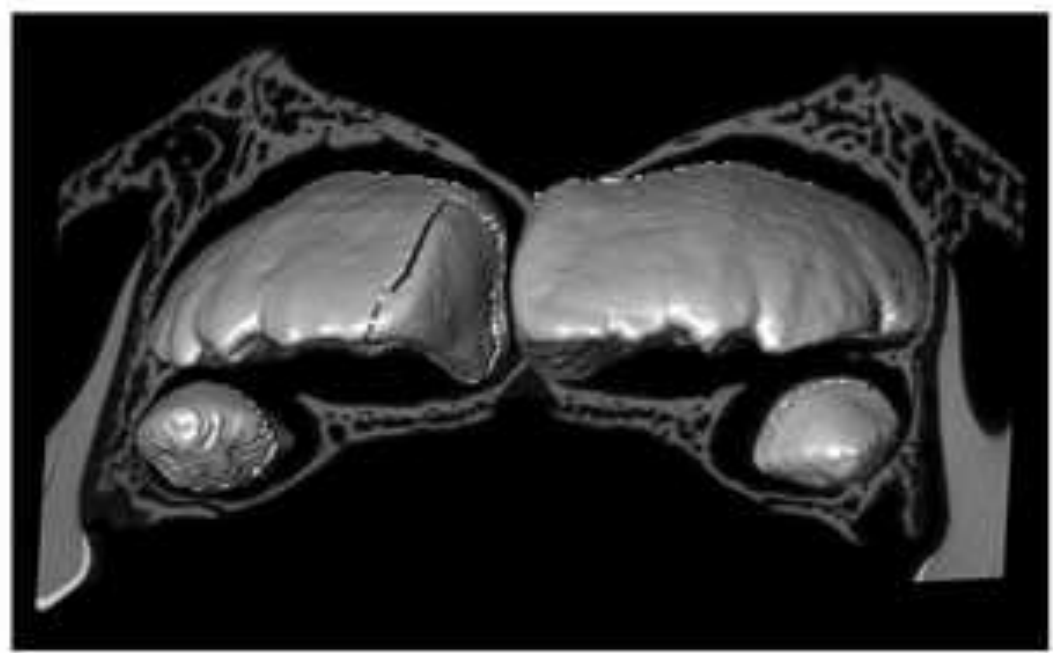

Incisal edges with crypt fenestration

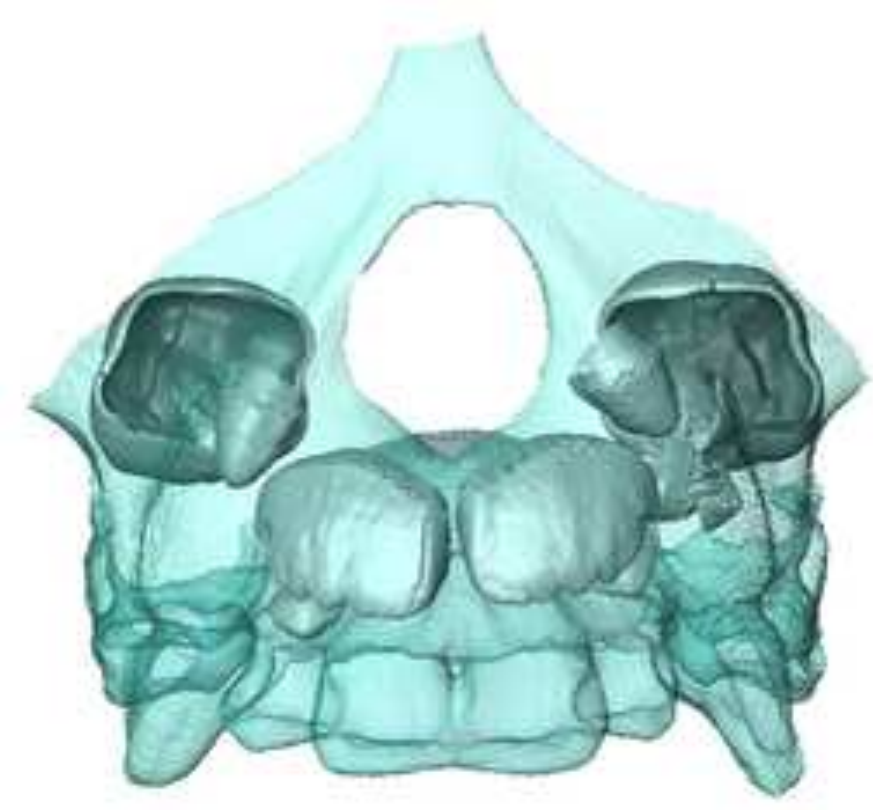

Tooth germs mesial view

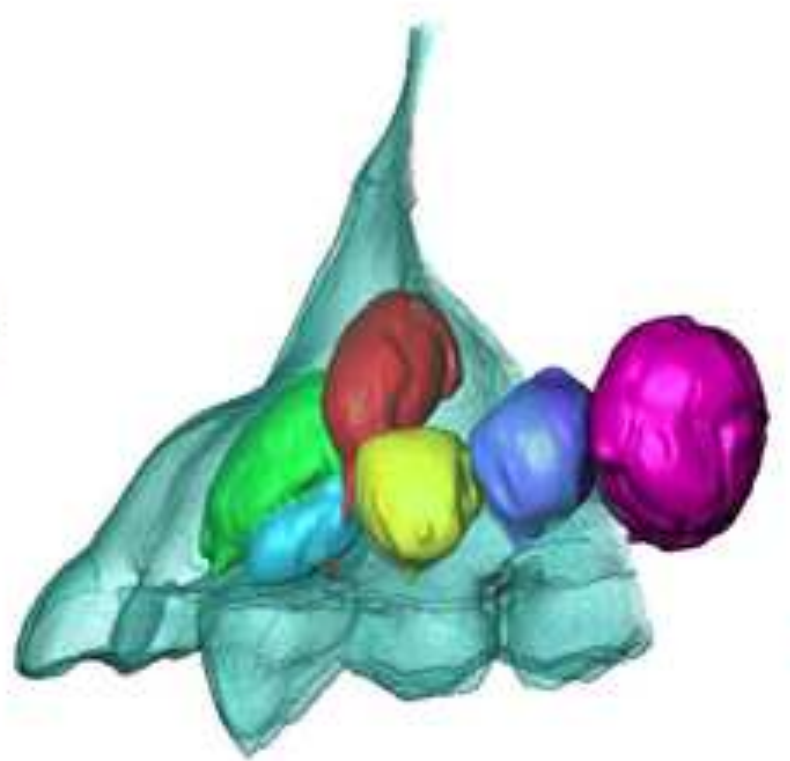

Crypts on left side

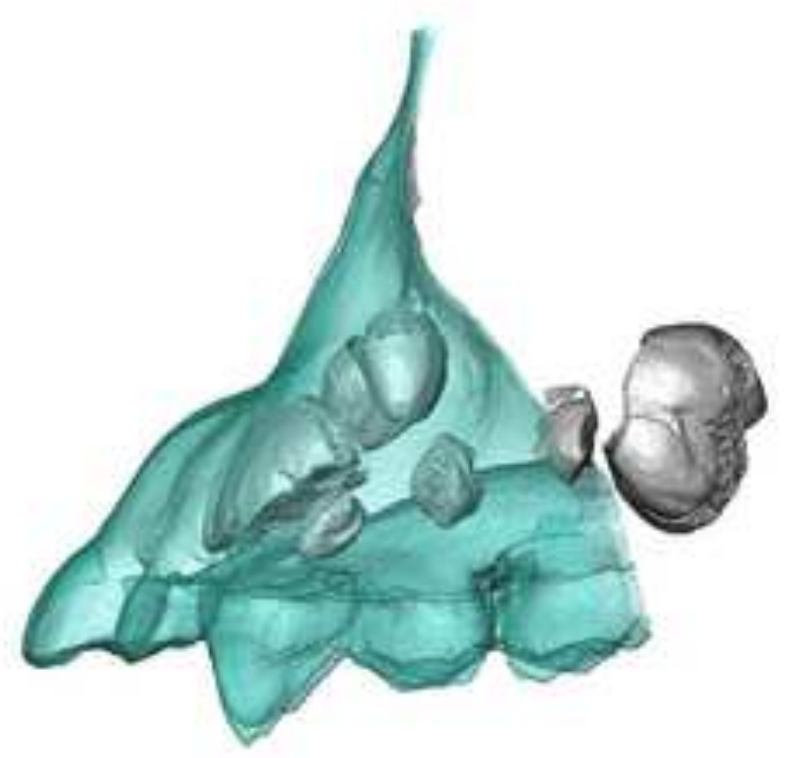

Germs on left side 


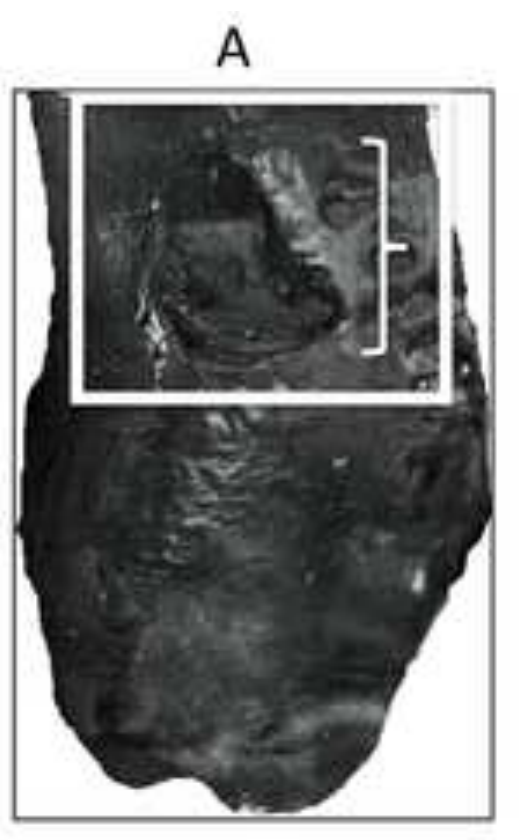

$\mathrm{N}-\mathrm{S}$ height $=3.43 \mathrm{~mm}$ Depth $=752 \mu \mathrm{m}$

E

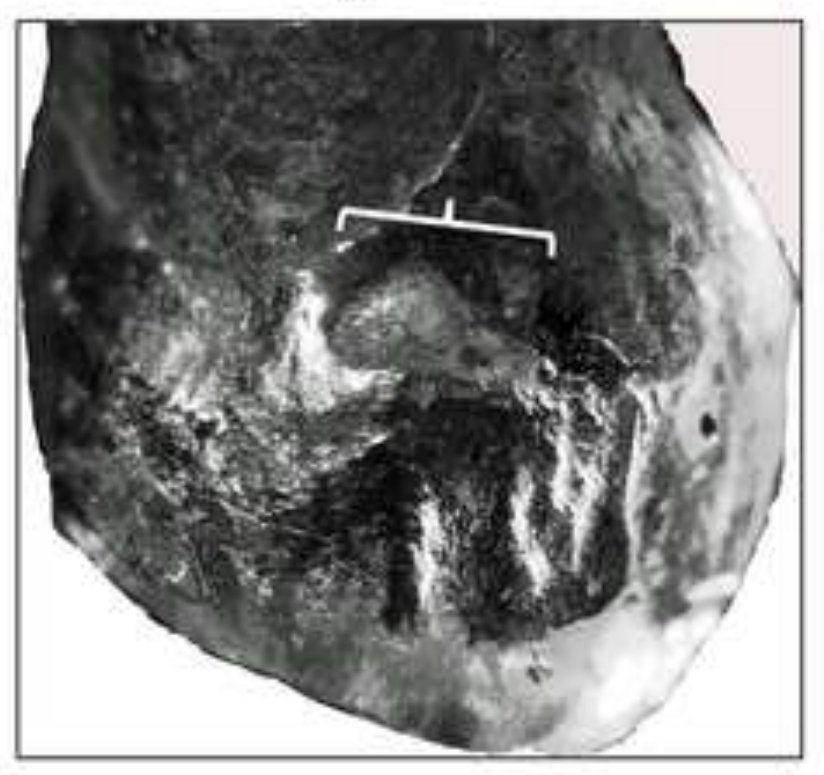

$\mathrm{N}-\mathrm{S}$ height $=1.00 \mathrm{~mm}$, Depth $=156 \mu \mathrm{m}$
B

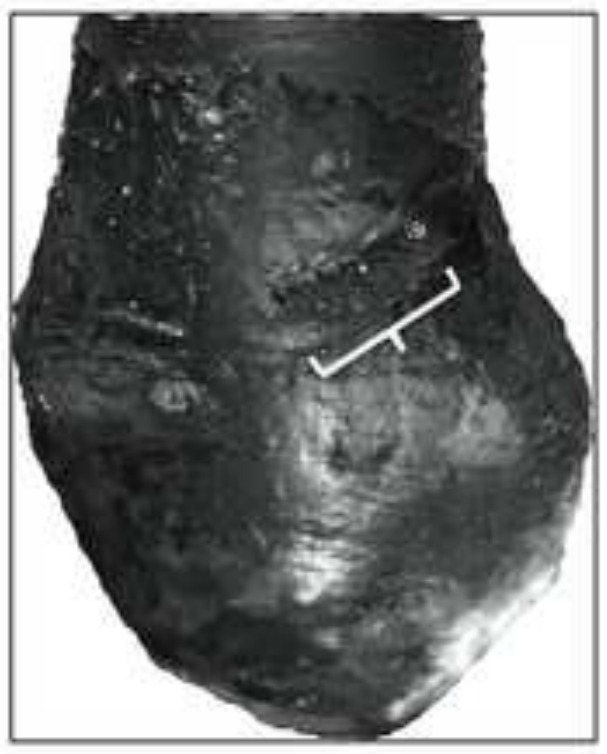

$\mathrm{N}-\mathrm{S}$ height $=1.19 \mathrm{~mm}$ $197 \mu \mathrm{m}$
C

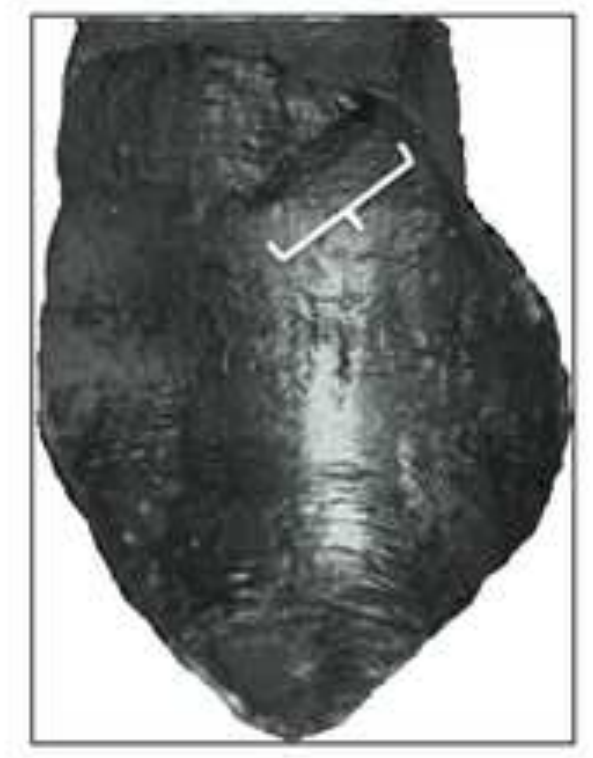

$\mathrm{N}$-S height $=1.84 \mathrm{~mm}$ $226 \mu \mathrm{m}$

F

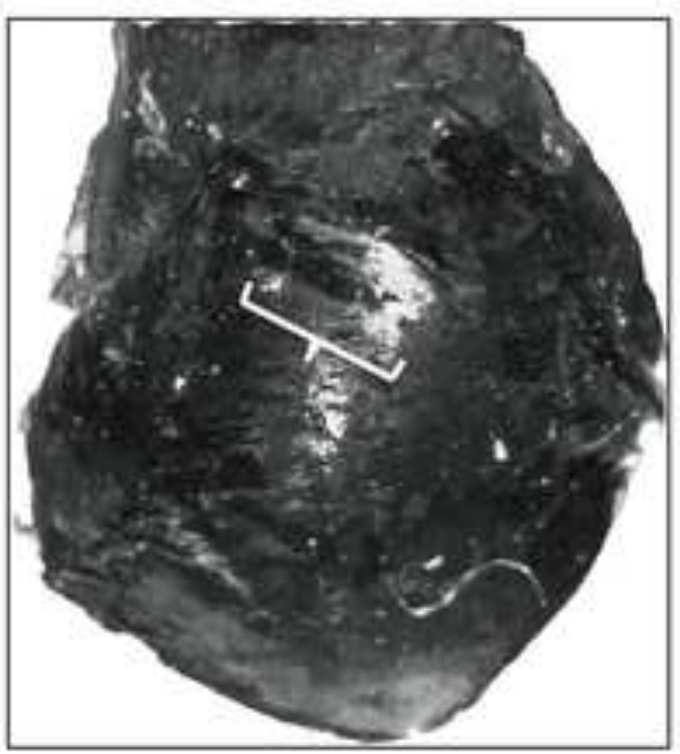

$\mathrm{N}-\mathrm{S}$ height $=0.868 \mathrm{~mm}$ $73 \mu \mathrm{m}$

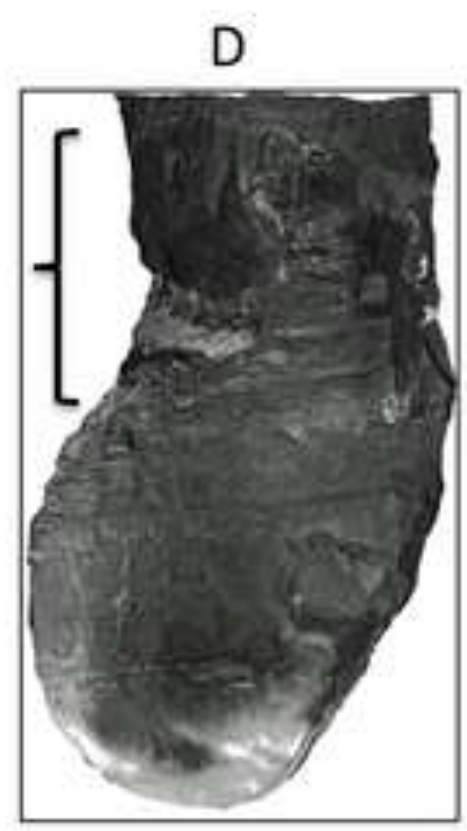

N-S height $=3.09 \mathrm{~mm}$ $872 \mu \mathrm{m}$

G

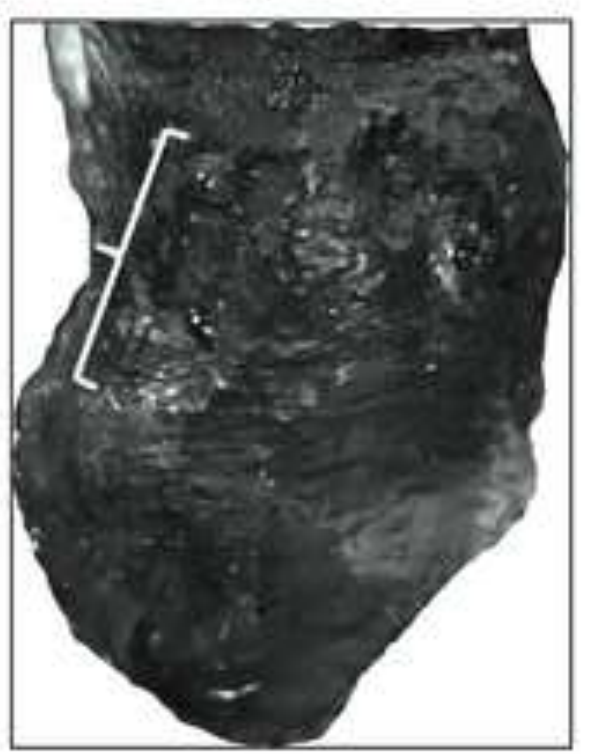

defect length $=3.74 \mathrm{~mm}$ $267 \mu \mathrm{m}$ 


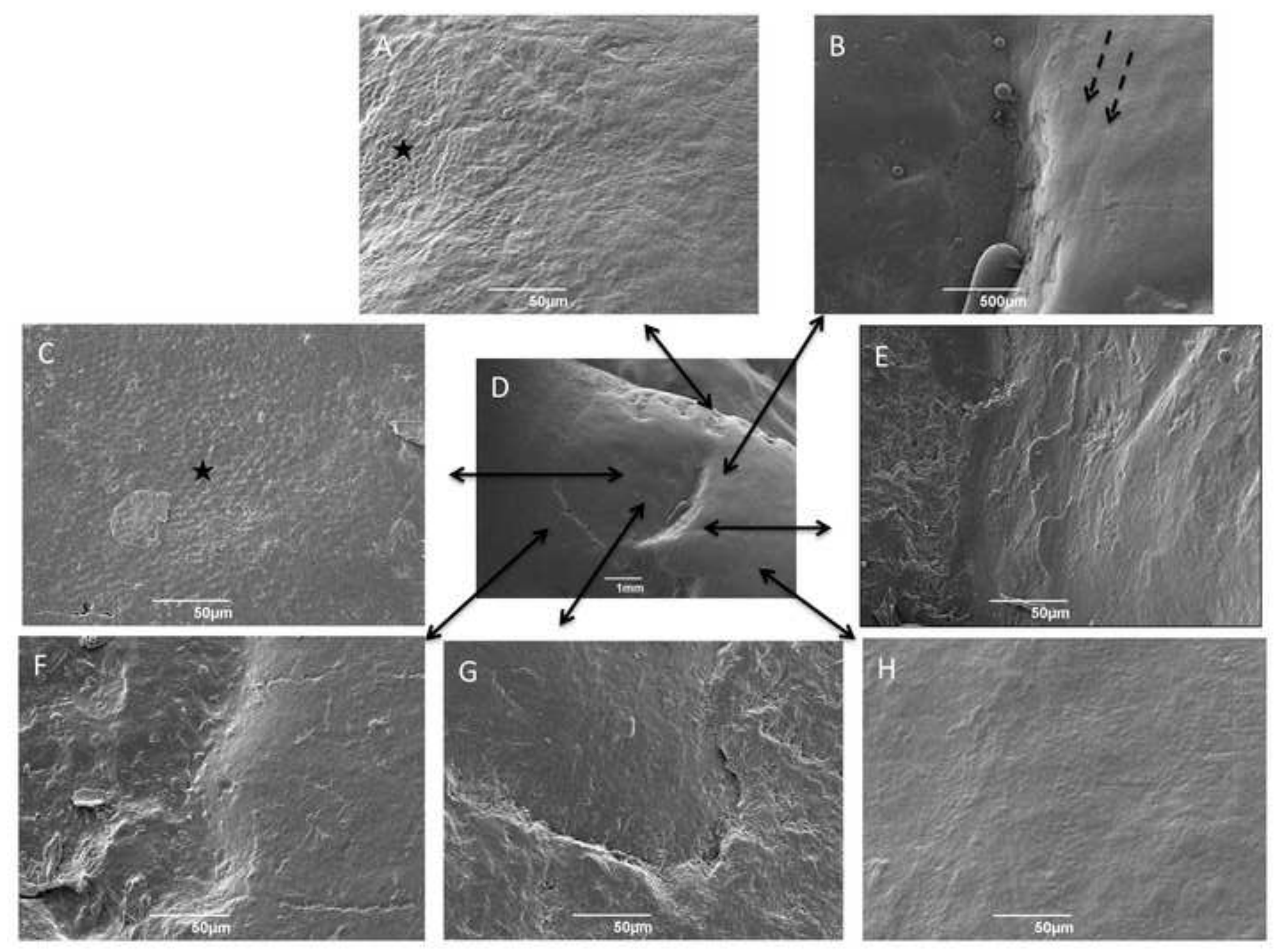

